\title{
Assessing the Control Systems Capacity for Demand Response in California Industries
}

Girish Ghatikar, Aimee McKane, Sasank Goli, Peter Therkelsen, Daniel Olsen Lawrence Berkeley National Laboratory

January 2012 


\section{Disclaimer}

This document was prepared as an account of work sponsored by the United States Government. While this document is believed to contain correct information, neither the United States Government nor any agency thereof, nor The Regents of the University of California, nor any of their employees, makes any warranty, express or implied, or assumes any legal responsibility for the accuracy, completeness, or usefulness of any information, apparatus, product, or process disclosed, or represents that its use would not infringe privately owned rights. Reference herein to any specific commercial product, process, or service by its trade name, trademark, manufacturer, or otherwise, does not necessarily constitute or imply its endorsement, recommendation, or favoring by the United States Government or any agency thereof, or The Regents of the University of California. The views and opinions of authors expressed herein do not necessarily state or reflect those of the United States Government or any agency thereof or The Regents of the University of California. 


\section{ACKNOWLEDGEMENTS}

The work described in this report was coordinated by the Demand Response Research Center and funded by the California Energy Commission (Energy Commission), Public Interest Energy Research (PIER) Program, under Work for Others Contract No. 500-03- 026 and by the U.S. Department of Energy under Contract No. DE-AC02-05CH11231.

The authors would like to acknowledge the contributions of all who assisted in review of this work, and thank them for their ongoing support, including PIER's Anish Gautam and Mike Lozano, and members of the Demand Response Research Center Industrial Controls Experts Working Group:

- Jim Filanc, Southern Contracting

- Steve Hiersche, Rockwell Automation

- Bob Holt, GE Power Systems

- Gary Marks, Iris Connection

- Rod Perry, Factory IQ

- Bill Schiel, Invensys

- Doug Scott, VaCom Technologies

- Dave Shroyer, Network Appliance

- Tom Taranto, Data Power Services

- Bill Wahl, Schneider Electric

- Bob Zak, Powerit Solutions

The authors would also like to thank Bunmi Adesola and Kristen Parrish of Lawrence Berkeley National Laboratory for their assistance in obtaining data for this report. 


\section{ABSTRACT}

California's electricity markets are moving toward dynamic pricing models, such as real-time pricing, within the next few years, which could have a significant impact on an industrial facility's cost of energy use during the times of peak use. Adequate controls and automated systems that provide industrial facility managers real-time energy use and cost information are necessary for successful implementation of a comprehensive electricity strategy; however, little is known about the current control capacity of California industries. To address this gap, Lawrence Berkeley National Laboratory, in close collaboration with California industrial trade associations, conducted a survey to determine the current state of controls technologies in California industries. This study identifies sectors that have the technical capability to implement Demand Response (DR) and Automated Demand Response (Auto-DR). In an effort to assist policy makers and industry in meeting the challenges of real-time pricing, facility operational and organizational factors were taken into consideration to generate recommendations on which sectors Demand Response efforts should be focused.

Analysis of the survey responses showed that while the vast majority of industrial facilities have semi- or fully automated control systems, participation in Demand Response programs is still low due to perceived barriers. The results also showed that the facilities that use continuous processes are good Demand Response candidates. When comparing facilities participating in Demand Response to those not participating, several similarities and differences emerged. Demand Response-participating facilities and non-participating facilities had similar timings of peak energy use, production processes, and participation in energy audits.

Though the survey sample was smaller than anticipated, the results seemed to support our preliminary assumptions. Demonstrations of Auto-Demand Response in industrial facilities with good control capabilities are needed to dispel perceived barriers to participation and to investigate industrial subsectors suggested of having inherent Demand Response potential.

Keywords: demand response, automated DR, openADR, industrial controls, dynamic pricing, controls and automation

Please use the following citation for this report:

Ghatikar, Girish, Aimee McKane, Sasank Goli, Peter Therkelsen, and Daniel Olsen (Lawrence Berkeley National Laboratory). 2011. Assessing the Control Systems Capacity for Demand Response in California Industries. California Energy Commission. Publication number: CEC-500-2011-026 


\section{TABLE OF CONTENTS}

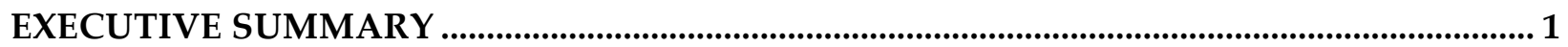

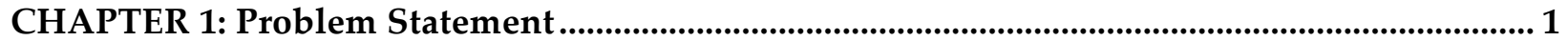

CHAPTER 2: Introduction, Background, and Report Organization ................................................ 2

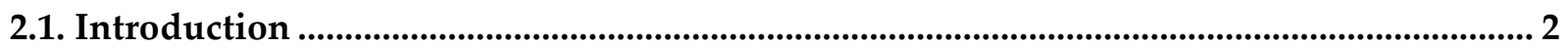

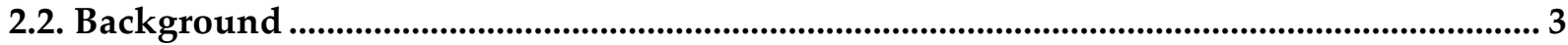

2.3. Report Organization.............................................................................................................................. 4

CHAPTER 3: Methodologies and the Survey Process ........................................................................ 6

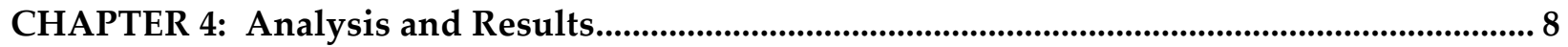

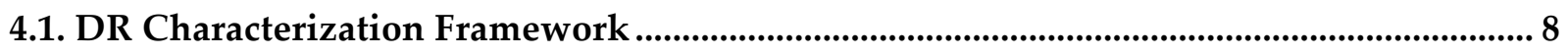

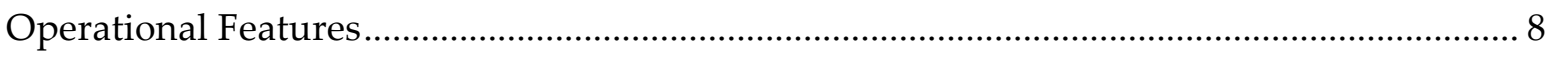

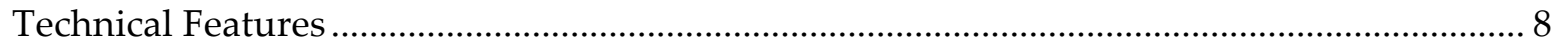

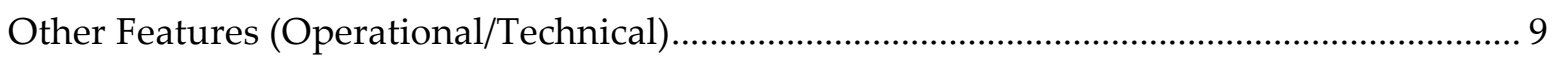

4.2. Summary of Survey Results ......................................................................................................... 9

Electrical Profile of Survey Respondents ............................................................................... 11

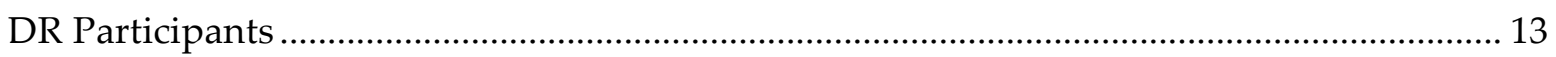

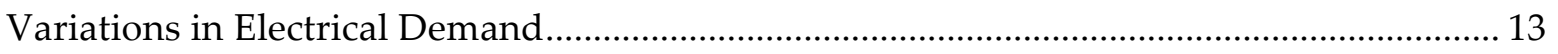

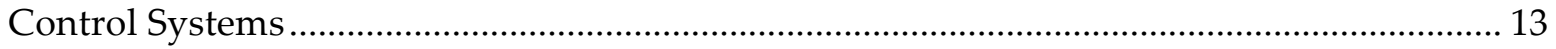

Respondent Production Characteristics .......................................................................... 15

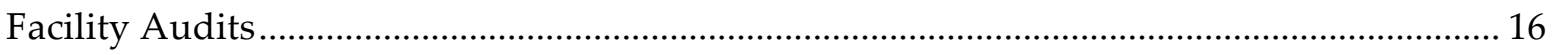

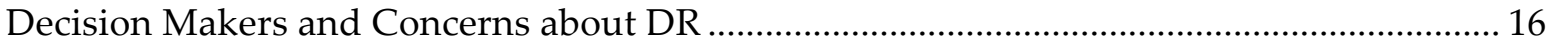

Desired Features/Benefits in DR Participation.................................................................. 17

4.3. Conclusions Drawn from Survey Responses ............................................................................ 18

4.4. Results Integrated with Other Sources...................................................................................... 19

4.5. Feedback from the Control Experts Group................................................................................. 20

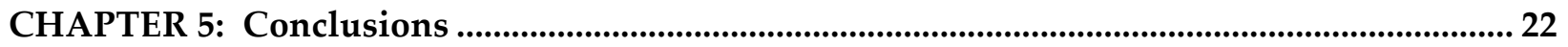

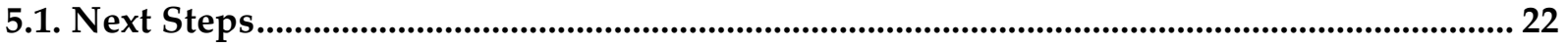

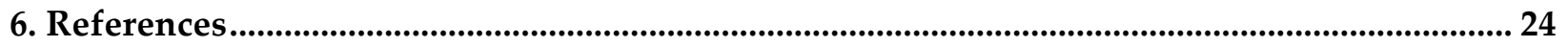


Appendix A: Common Types of Controls and Terminology

Appendix B: Open Automated Demand Response (OpenADR) Technology Overview

Appendix C: Graphical Representations of Survey Results

Appendix D: Survey Questionnaire Submitted to Respondents

Appendix E: Control Expert Feedback Form

\section{List of Figures}

Figure 1: Methodology and Approach Used for Controls Survey ................................................ 6

\section{List of Tables}

Table 1: Demand Response Characterization Framework.....

Table 2: Industrial Mix and DR Categorization of Survey Respondents ...................................... 11

Table 3: Service Providers Supplying Purchased Electricity ....................................................... 12

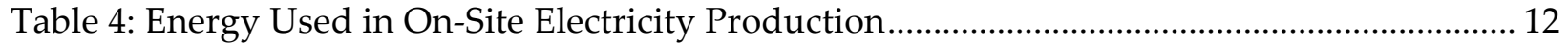

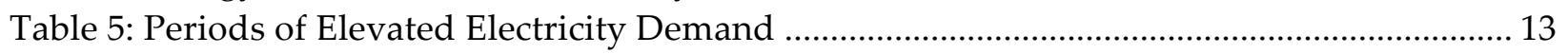

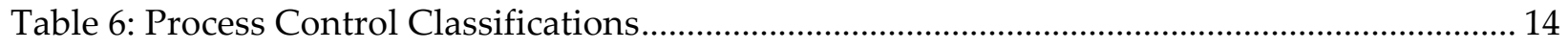

Table 7: Control System Vendor Used at Reporting Facilities ....................................................... 14

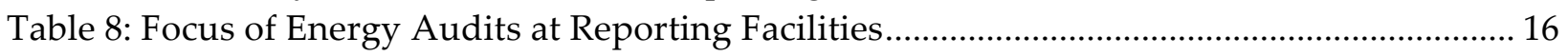

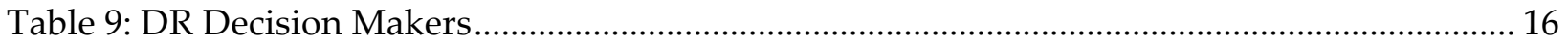

Table 10: Preferred Features for Auto-DR Program …............................................................... 18

Table 11: Annual Electricity Consumption for Subsectors with Suggested DR Potential............. 21 


\section{EXECUTIVE SUMMARY}

\section{Introduction}

The capabilities of industrial facilities control systems influence a facility's ability to use energy efficiently. Control capabilities enable a range of energy management techniques, including participation in Automated Demand Response programs.

\section{Purpose}

Due to a lack of information on the current state of controls in California industry, an effort was undertaken by Lawrence Berkeley National Laboratory (LBNL) beginning in 2009 to investigate the status of industrial controls and the link between control capabilities and Demand Response participation.

\section{Project Objectives}

A survey was designed to gather information on facilities' control capabilities, as well as other factors believed to be pertinent to Demand Response participation. The survey was tested and deployed via a web-based tool, and survey responses were analyzed to ascertain the prevalence of sophisticated control systems and the validity of the researchers' assumptions regarding the link between facilities' operational and technical characteristics and their Demand Response potential. Outreach by Lawrence Berkeley National Laboratory and various industry contacts yielded 46 valid survey responses. Preliminary findings obtained from these responses were presented to a group of industrial control experts, whose feedback was used to refine the conclusions.

\section{Conclusions}

Analysis of the survey responses received showed that while the vast majority of industrial facilities have semi- or fully automated control systems, participation in Demand Response programs is still low due to perceived barriers. The results also showed that the facilities that use continuous processes are good Demand Response candidates. When comparing facilities participating in Demand Response to those not participating, several similarities and differences emerged. Demand Response-participating and non-participating facilities had similar timings of peak energy use, similar production processes, and similar participation in energy audits. The key characteristics of Demand Response-participating facilities are:

- Higher energy consumption

- More automated controls

- More centralized controls

- Use of controls for peak management

- Facilities with on-site generation

- Delegation of Demand Response decision-making authority to production and facility-level staff 
The results of the aggregated analysis were compared against two additional sources of information: (1) electricity meter data from a survey respondent attempting load shifts, and (2) feedback from the control experts. In both cases, the additional information agreed with the research team's characterization of Demand Response-enabling attributes. The feedback from the control experts was also used to suggest industrial subsectors with unharnessed Demand Response potential.

\section{Recommendations}

Though the survey sample of industrial facilities was smaller than anticipated, the results seemed to support our preliminary assumptions. Future work yielding more information on the control capabilities of California industrial facilities and their potential for Demand Response could include obtaining a larger survey response data set from which to draw conclusions. Demonstrations of Auto-Demand Response in industrial facilities with good control capabilities are needed to dispel perceived barriers to participation, and investigating industrial subsectors suggested of having inherent Demand Response potential.

\section{Benefits to California}

California's electricity markets are moving toward dynamic pricing models, such as real-time pricing, within the next few years, which could have a significant impact on an industrial facility's cost of energy use during the times of peak use. The findings from this report, and partnership with key industrial trade associations, will help the California industries develop a comprehensive strategy for responding to electricity price and reliability signals, to achieve a competitive advantage over those that do not. Better understanding of the state of controls and automation will help facility managers gain real-time access to both energy use and cost information.

The results from this report will contribute to the industry's technical capacity to voluntarily receive and respond to open automated demand response (Open Auto-DR) signals, currently offered by California investor-owned utilities. The results also provide an understanding of shifting or shedding non-essential electrical load, and, more importantly, help shape public policies to effectively assist industry in meeting the challenges of real-time pricing in California. 


\section{CHAPTER 1: Problem Statement}

California's electricity markets are moving toward dynamic pricing (e.g., real-time pricing) within the next few years. This change could have a significant impact on facilities' cost of electricity during times of peak use. An industrial facility with a comprehensive strategy for responding to electricity price and supply signals will have a competitive advantage over those that do not.

The industrial facility of the future will have the capability to extract the maximum physical and monetary value from the energy used on their premises. In addition, these facilities will possess sufficient real-time energy information and control capability to decide when and how much energy to use or store for later use, based on its price, source, and other factors valued by facility managers. For some facilities, onsite energy production will allow them to become net suppliers to the grid during peak periods (McKane, Rhyne et al. 2009).

Elements of a comprehensive strategy for responding to electricity price and supply signals include the following:

- Energy Efficiency: Optimizing electricity use and cost.

- Demand Limiting: Managing electricity demand on a daily basis below a pre-determined upper limit.

- Load Management: Reducing demand charges on a daily basis by smoothing out peaks in usage.

- Demand Response (DR): Participating in occasional events (and receiving incentives) to temporarily reduce consumption when prices and demand on the electrical grid are at their highest. Automated Demand Response (Auto-DR) is a type of DR that uses a secure signal between the utility and the customer facility to automatically shed or shift specified loads under predetermined, mutually agreed upon, conditions.

Although adequate controls and automated systems that provide industrial facility managers real-time energy use and cost information are necessary for successful implementation of a comprehensive electricity strategy, little is known about the current control capacity of California industries. To address this gap, Lawrence Berkeley National Laboratory (LBNL), in close collaboration with California industrial trade associations, conducted a survey to determine the current state of controls technologies in California industries. This study identifies sectors that have the technical capability to implement DR and Auto-DR. Further, in an effort to assist policy makers and industry in meeting the challenges of real-time pricing, facility operational and organizational factors were taken into consideration to generate recommendations on which sectors DR efforts should be focused. 


\section{CHAPTER 2: Introduction, Background, and Report Organization}

\subsection{Introduction}

The LBNL survey, funded by the California Energy Commission's Public Interest Energy Research (PIER) program, was designed to better understand the existing control and automation capabilities in California industries and near-term plans for upgrades. The resulting information is intended to increase the understanding of industry's capacity to voluntarily receive and respond to Automated Demand Response (Auto-DR) signals to shift or shed nonessential electrical load. While the focus of this survey was to identify control and automation capacity, the questions and analysis of results also identified operational and organizational characteristics and strategies for DR within different industrial sectors, as they are important factors used to determine DR participation.

During the survey process, we were able to reach 59 industrial facilities, with the preponderance of respondents from the food processing and wastewater sectors. The survey process and its results are summarized in this report and further detailed in the appendices. In addition, the data collected from refrigerated warehouses, wastewater facilities, industrial gases, and data centers as the result of previous LBNL research (integrated audits, fieldwork, and sector-based analyses) were used to validate assumptions on attributes within these industrial sectors that contribute to DR potential (Ghatikar et al. 2010; Lekov et al. 2009a; Lekov et al. 2009b; Thompson et al. 2010).

The research was intended to answer several key questions in order to identify DR capacity in the industrial facilities. It consisted of three main tasks. First, identify which industries have the greatest automated controls capability, which industries have the greatest shed/shift capacity, and the similarities among these industries. Second, identify the relationships between automated controls capacity, history of energy efficiency measures, and DR participation. Finally, identify other factors, such as organizational structure and impact to DR participation.

A comprehensive web-based survey was designed as a tool to gather information on the industrial facilities. The industrial facility responses to these questions were analyzed and reviewed by a group of industrial experts in controls and automation.

The group of industrial control systems experts was invited to form a Technical Advisory Group (TAG) for the following purposes:

- Validating or refining the findings from the draft report.

- Expanding our understanding of the controls environment for other industrial sectors of importance to California.

- Discussing the capabilities of these additional sectors to participate in DR.

- Refining the analysis for final recommendations. 
Based on prior Demand Response Research Center (DRRC) research, the following additional sectors were identified as likely to have DR potential (McKane, Piette et al. 2008a):

- Converted Paper Product Manufacturing

- Basic Chemical Manufacturing in Addition to Industrial Gases

- Dairy Product Manufacturing

- Aerospace Product and Parts Manufacturing

- Other Fabricated Metal Product Manufacturing

- Animal Slaughtering and Processing

- Bakeries and Tortilla Manufacturing

- Beverage Manufacturing

Input from these experts was sought via email correspondence and by hosting a meeting at LBNL on February 10, 2011. In preparation for the TAG meeting, a template of DR characteristics was developed, which provided a framework for obtaining expert input both during and after the meeting.

After expert input was obtained and integrated, a final draft report was prepared and circulated for peer review. This final report resulted from these peer reviews. The purpose of this final report is to provide guidance to policy makers on (1) the status of industrial control systems in California industries, and (2) the barriers that need to be addressed to prepare California industries to have the capability to extract the maximum physical and monetary value from the energy used on their premises.

\subsection{Background}

The market for facility-wide energy management and controls is growing quickly, as is the need for Auto-DR, which offers full end-to-end automation for increased DR reliability (Katipamula and Gaines 2003). To date, the focus has been on load management-a relatively simple approach directed toward reducing demand charges-but this is expected to change, primarily driven in California by the convergence of dynamic pricing, greater access to lower-cost and more-sophisticated control strategies, and the emergence of energy management systems. The Auto-DR program managed by the California utility, Pacific Gas and Electric Company (PG\&E) offered incentives for participation by the commercial and industrial customers. The PG\&E Technology Assistance and Technology Incentives funding for enabling technologies have totaled $\$ 300 /$ kilowatt $(\mathrm{kW})$ for the summers of 2007, 2008, and 2009. This has resulted in nearly 50 megawatts (MW) of total enrolled load in the Auto-DR program within the PG\&E territory alone (Katipamula and Gaines 2003).

Industrial machinery and process systems have the potential to take advantage of DR opportunities and increase their energy efficiency (McKane, Piette et al. 2008a). The emergence 
of centralized system-level network controls provides the missing link to allow improved demand management of energy systems. The complete integration of load management, DR, and energy efficiency across an entire industrial facility may soon become a commonplace. Industrial plants without onsite generation could, under certain conditions, derive financial benefits and contribute to the economic health of their businesses while preserving system reliability and managing the cost of electricity delivery (McKane, Rhyne et al. 2008b). Industrial controls include systems and configurations (sometimes integrated) to manage process loads, utilities such as compressed air and steam, local operations, building systems, and business systems. Such a system to monitor and control energy use is commonly known as an Energy Management Control System (EMCS). ${ }^{1}$ For more information about industrial control systems and terminologies, see Appendix A.

Understanding the functional capabilities of these control systems, including the underlying technologies and software capabilities as installed, is essential to identify and quantify a specific facility's potential to participate in the full range of electricity management options while maintaining day-to-day business or industry operations. It is especially critical for participation in Auto-DR or implementation of Open Auto-DR standards (OpenADR) (Piette, Ghatikar et al. 2009). OpenADR refers to data models that offer open standards-based information exchange for automating price and reliability DR events (See also Appendix B).

For the purpose of this report, the industrial systems for production or processes are classified as:

- Manual: Manually turning off or changing set points or processes for each switch, controller, or piece of equipment.

- Semi-Automated: Automation of one or several processes or systems within a facility using a control system, with the remainder of the facility under manual operations.

- Fully Automated: Automation of an entire facility, with integration of end-use loads into a control system, centrally managed with minimal human intervention.

These industrial systems can also be decentralized with islands of automation and controls within a facility.

\subsection{Report Organization}

Section 3 of this report describes the methodologies used to collect data on functional capabilities of control systems within industrial facilities. Section 4 describes the analysis of the data and results, and Section 5 describes conclusions and recommendations.

${ }^{1}$ EMCS consists of the data measurement, transmission, and analysis infrastructure required to achieve this functionality. It is often referred to by other terms, including building automation system (BAS), building management system (BMS), energy management system (EMS), and facility management system (FMS). 
Appendices A and B contain background information on industrial controls systems and OpenADR, respectively. Appendix C contains graphical interpretations of survey responses. Appendix D contains the questions of the controls survey. 


\section{CHAPTER 3: \\ Methodologies and the Survey Process}

Figure 1 summarzes the methodologies and approaches used for the survey.

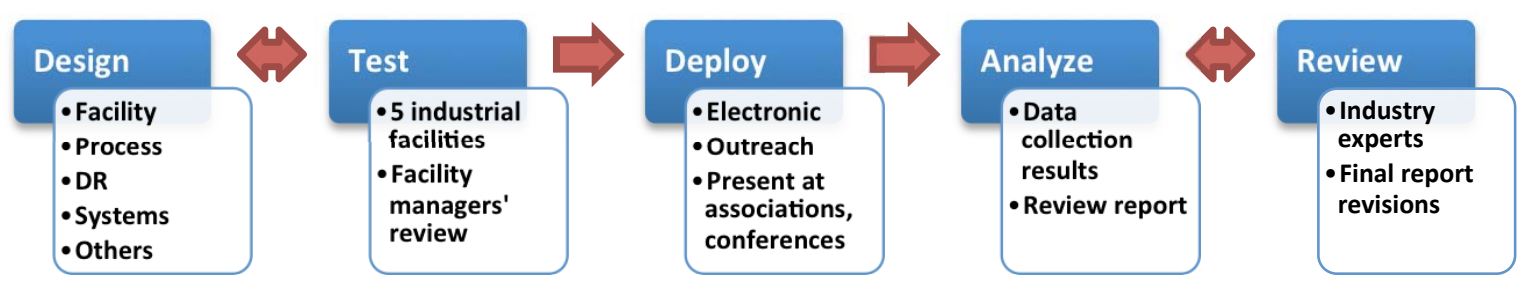

Figure 1: Methodology and Approach Used for Controls Survey

The survey was designed with review from trade associations and the California Energy Commission (Energy Commission). The survey was designed to be a simple set of Yes or No $(\mathrm{Y} / \mathrm{N})$ questions and/or multiple-choice responses. The design focused on facility information (e.g., industry type, electricity use), process systems, support, connected and peak loads, DR potential (e.g., DR audit, decision maker), controls (e.g., EMCS, automation), IT systems, security, and other miscellaneous information. The full survey can be found in Appendix D.

After design, the survey was tested, with assistance from trade associations, within five facilities (water-wastewater, brewery, refrigerated warehouse, and food processing facilities). The in-person survey tests showed that a facility manager could respond to most of the questions in 10 to 20 minutes; however, it was noted that further input from others, such as the production manager and information technology specialist, could be needed.

The final revised survey was deployed using a web-based tool for ease of response, data collection, and analysis. The trade associations, the Energy Commission, and industry acquaintances conducted outreach to find survey respondents. Lawrence Berkeley National Laboratory conducted presentations at trade associations and conferences and contacted facilities via phone. Some significant challenges were encountered in securing a sufficient number of respondents across a range of industrial sectors. In general, there were challenges in obtaining the data due to the lack of understanding of the future impact of dynamic pricing and the potential for DR to assist in addressing these impacts. A limited budget precluded securing the services of a professional market research firm.

The results were identified by data analysis for further review by industry experts. The analyses were based on 46 responses from diverse California industrial facilities, collected over a six-month period. Two more responses were gathered after the experts meeting, which got the total to 48. All responses were aggregated for reporting purposes to protect the identities of the responding facilities. 
Expert review of the analysis and recommendations was obtained via a meeting of industrial control systems experts at LBNL, where preliminary findings were presented and discussed. The final revision of this report reflects that input. 


\section{CHAPTER 4: Analysis and Results}

For evaluation of the survey respondents' ability to participate in DR programs using Auto-DR and automated end-use strategies, their responses were analyzed against a characterization framework. This characterization framework had been formulated to facilitate a structured assessment of whether or not the industry was a good candidate for Auto-DR based on its operational and technical capabilities. Additional analysis was also done, which included checking the survey's conclusions against data from a brewery for which LBNL had meter and audit information, and vetted against feedback from the control systems experts' meeting.

\subsection{DR Characterization Framework}

To assess the DR potential and ability of industry to participate in Auto-DR and dynamic pricing programs, a characterization framework was created based on both operational and technical functional capabilities, as well as anecdotal and intuitive findings. Identifying the characteristics common to industries that have successfully implemented DR may help identify additional sectors of potential for Auto-DR. The framework gauges DR automation potential of an industry and ability to participate in a specific program as a precursor to the disaggregation of the control survey results. For example, curtailment of certain loads may require advance notification (Thompson et al. 2010).

\section{Operational Features}

1. Load Variability and Profile: Low load variability or consistent load profile leads to predictable loads during peak periods, which permits advance planning to curtail or shift these loads away from peak periods. Along with peak electricity use and costs, this also facilitates advance demand reduction estimation for the service provider and assessment of financial benefits of a facility participating in DR.

2. Seasonal Variations: Seasonal variations in facility processes can lead to periods of increased electricity use. Facilities that experience these peaks may be fully utilizing their existing assets (thermal and/or material storage, equipment capacity, etc.) during these periods at the same time that a DR shed or shift is most valuable for the utility grid. Conversely, facilities that either experience limited seasonal variations or those with periods of peak usage not coincident with high demand periods would more likely be good candidates.

3. Process Classification: The complexity of industrial processes (e.g., batch vs. continuous) influences DR participation capability. Batch processes were thought to have greater flexibility for load shifting than continuous ones, as they have in-process material storage reserves, and starts/stops are routine.

\section{Technical Features}

1. Controls Automation Capabilities: Prior audits and studies have suggested that advanced controls and automation (e.g., control systems, sub-metering) improve reliability of DR participation (Piette, Kiliccote et al. 2009). 


\section{Other Features (Operational/Technical)}

1. Anecdotally, DR participation is based on facility understanding of energy management practices, incentives, audits, studies, and other factors (e.g., opportunities for refrigerated warehouses and data centers (Ghatikar 2010; Lekov 2009a), demand-side management expertise). Newer or less "sophisticated" industries with good Auto-DR capabilities, such as agricultural irrigation, may be overlooked.

2. The larger the size of the industry in question, all other factors equal, the less the overall technology development and recruitment efforts are likely to cost on a per-kilowatt basis. Economics is yet another factor in evaluating the marginal cost of adding Auto-DR capabilities.

Table 1 shows the characterization framework of anecdotal and intuitive findings, which are used as a reference to disaggregate and present the survey results.

Table 1: Demand Response Characterization Framework

\begin{tabular}{|c|c|c|c|c|}
\hline Attribute & Category & Characteristic & DR Potential & Notes \\
\hline \multirow{2}{*}{$\begin{array}{l}\text { Load } \\
\text { Variability/Profile }\end{array}$} & \multirow{2}{*}{ Operational } & High & Low & \multirow{2}{*}{$\begin{array}{l}\text { Predictable peak loads } \\
\text { permit advance planning } \\
\text { to shed/shift loads. }\end{array}$} \\
\hline & & Low & High & \\
\hline \multirow{2}{*}{$\begin{array}{l}\text { Seasonal } \\
\text { Variations }\end{array}$} & \multirow{2}{*}{ Operational } & High & Low & \multirow{2}{*}{$\begin{array}{l}\text { Grid peak coincident } \\
\text { plant operational peaks } \\
\text { lessen the DR potential. }\end{array}$} \\
\hline & & Low & High & \\
\hline \multirow{2}{*}{$\begin{array}{c}\text { Process } \\
\text { Classification }\end{array}$} & \multirow{2}{*}{ Operational } & Continuous & Low & \multirow{2}{*}{$\begin{array}{l}\text { Batch process more } \\
\text { flexible for DR. }\end{array}$} \\
\hline & & Batch & High & \\
\hline \multirow{2}{*}{$\begin{array}{l}\text { Controls } \\
\text { Capabilities }\end{array}$} & \multirow{2}{*}{ Technical } & Basic & Medium & \multirow{2}{*}{$\begin{array}{l}\text { Advanced controls allow } \\
\text { for automation resulting } \\
\text { in reliable/ consistent load } \\
\text { shift. }\end{array}$} \\
\hline & & Advanced & High & \\
\hline \multirow[b]{2}{*}{$\begin{array}{l}\text { Enablement } \\
\text { Costs }\end{array}$} & \multirow[b]{2}{*}{ Other } & High & Low & \multirow{2}{*}{$\begin{array}{l}\text { Per capita enablement } \\
\text { costs may be lesser in } \\
\text { larger sectors due to high } \\
\text { load availability for same } \\
\text { effort. }\end{array}$} \\
\hline & & Low & High & \\
\hline \multirow{2}{*}{ DR History } & \multirow{2}{*}{ Other } & No & High/Low & \multirow{2}{*}{$\begin{array}{l}\text { DR history will give } \\
\text { better indication of future } \\
\text { participation. }\end{array}$} \\
\hline & & Yes & High/Medium & \\
\hline
\end{tabular}

\subsection{Summary of Survey Results}

Analysis was conducted on the 59 submitted surveys received before the control experts meeting, after which a final effort was made to obtain survey responses based on leads from the meeting attendees. This yielded two additional valid responses, but they did not deviate significantly from the original set, and did not warrant reanalysis of the results. 
Of the 59 submitted surveys, 13 were removed, as they were non-industrial respondents, not located in California, submitted erroneous data, or were facilities that used less than $200 \mathrm{~kW}{ }^{2}$ Valid survey responses are organized by industry type and associated four-digit North American Industry Classification System (NAICS) code in Table 2. ${ }^{3}$ The 46 responses represent 16 unique industry sectors (see Figure C-1 in Appendix C). Nine of the responses are from water-wastewater treatment facilities and 18 from fruit and vegetable processors. The remaining 19 responses represent a variety of industries, each with one or two responses. Due to the low response rate for the wide range of represented sectors, aggregated analysis is presented.

\footnotetext{
${ }^{2}$ The requirements for selecting industries with electricity use of $200 \mathrm{~kW}$ or above were based on commercial Auto-DR programs of California investor-owned utilities that focus on large commercial and industrial facilities.

${ }^{3}$ The NAICS code was "developed as the standard for use by Federal statistical agencies in classifying business establishments for the collection, analysis, and publication of statistical data related to the business economy of the United States." (http://www.naics.com/faq.htm)
} 
Table 2: Industrial Mix and DR Categorization of Survey Respondents

\begin{tabular}{|c|l|c|c|c|c|}
\hline NAI CS & \multicolumn{1}{|c|}{ Industrial Sector } & $\begin{array}{c}\text { Respondent } \\
\text { Total }\end{array}$ & $\begin{array}{c}\text { Respondents } \\
\text { Participating } \\
\text { in DR }\end{array}$ & $\begin{array}{c}\text { Respondents } \\
\text { Not } \\
\text { Participating } \\
\text { in DR }\end{array}$ & $\begin{array}{c}\text { Respondents } \\
\text { Energy Use } \\
\text { ( MW) }\end{array}$ \\
\hline 2213 & Water-Wastewater Treatment & 9 & 3 & 6 & 39.0 \\
\hline 3114 & Fruit and Vegetable Processing & 18 & 2 & 16 & 122.3 \\
\hline 3121 & Beverages & 2 & 1 & 1 & 25.0 \\
\hline 3241 & Petroleum/Coal & 1 & & 1 & 0.8 \\
\hline 3254 & Pharmaceuticals/Medicine & 1 & & 1 & 7.5 \\
\hline 3272 Glass & 2 & 2 & & 15.0 \\
\hline 3273 Cement and Concrete & 2 & 1 & 1 & 52.5 \\
\hline 3274 & Gypsum & 1 & 1 & & 2.5 \\
\hline 3344 & Semiconductor/Electronics & 2 & 1 & 1 & 3.3 \\
\hline 3363 & Motor Vehicle Parts & 1 & 1 & & 2.5 \\
\hline 4869 & Petroleum Transportation & 1 & 1 & & 62.5 \\
\hline 4881 & Airport & 1 & 1 & 1 & 25.0 \\
\hline 4931 & Warehousing and Storage & 1 & & 1 & 2.5 \\
\hline 5182 & Data Centers & 2 & 1 & 1 & 2.0 \\
\hline 5622 & Waste Treatment and Disposal & 1 & 1 & 1 & 2.5 \\
\hline 9261 & Transportation Authority & $\mathbf{4 6}$ & $\mathbf{1 5}(33 \%)$ & $\mathbf{3 1}(67 \%)$ & $\mathbf{3 9 0 . 3}$ \\
\hline & TOTAL & & & \\
\hline
\end{tabular}

Additionally, Table 2 provides information on current DR participation for represented industrial sectors. In aggregate, approximately one-third of respondents were participants in a DR program and two-thirds were not (see figures C-2 and C-3).

\section{Electrical Profile of Survey Respondents}

In line with the survey protocol, responses were elicited in ranges of energy usage and expenditure. The midpoints of these ranges were used in our analysis. Therefore, the results should be considered representative, not exact.

The 46-survey respondents' total electricity demand is $390.3 \mathrm{MW}$. Of this total, facilities participating in a DR program demand $183 \mathrm{MW}$ (47 percent) while non-DR facilities comprise the remaining $207 \mathrm{MW}$ (53 percent). Forty-three percent (167.5 MW) of the total energy demand is consumed by the four most energy intensive facilities. These facilities include a petroleum transporter (62.5 MW), an airport (45 MW), a cement and concrete facility (35 MW), and a fruit and vegetable processer (25 MW) (see Figure C-4). The petroleum transporter and airport are DR participants, while the other two facilities are not. Of the remaining 42 facilities, the next most energy-intensive facility requires only $17.5 \mathrm{MW}$, or 8 percent of the remaining loads. DR participants use an average of $12.2 \mathrm{MW}$ per facility, nearly twice the 6.7 MW that an average non-DR facility demands.

All 15 DR participating facilities and 19 of 31 (61 percent) non-DR facilities reported peak electrical power demand rates. Together, all reporting facilities demand $332 \mathrm{MW}$ of peak electricity (see Figure C-5). Approximately 40 percent (130 MW) of the total peak power is used by three facilities, all DR participants. These facilities include the same petroleum transporter and airport as mentioned before, and a different cement and concrete plant. On average, DR participating facilities have peak demand of 13.3 MW, and non-DR facilities have peak demand 
of 7.0 MW. All DR-participants reported knowledge of which end-uses are responsible for peak loads, compared to 78 percent of non-DR facilities.

Of the 46 respondents, all 15 DR participating facilities and 25 of 31 (80 percent) non-DR facilities reported annual electricity expenditure data. For all facilities, expenditures totaled \$214 million (see Figure C-6). Thirty percent (\$65 million) is associated with the three largest energy consumers, a petroleum transporter (\$25 million), an airport (\$25 million), and a cement and concrete plant (\$15 million) - all of which participate in DR programs. An average electricity rate of 9.5 cents per kilowatt-hour $(\$ / \mathrm{kWh})$ was paid.

Forty-three facilities reported the source of their electricity purchases. Service providers and number of survey customers are listed in Table 3 (see Figure C-7). Forty-six percent of respondents purchase electricity from PG\&E. The breakdown of PG\&E customers with and without DR programs mirrors the ratio of all survey respondents: 38 percent with a DR program and 62 percent without. The other 14 respondents purchase electricity from Southern California Edison (4), San Diego Gas and Electric (2), directly from a generator (1), a municipality (2), or an irrigation district (5). Facilities purchasing from these other service providers have a roughly even split between DR participating facilities and non-DR facilities.

Table 3: Service Providers Supplying Purchased Electricity

\begin{tabular}{|l|c|c|c|c|c|c|}
\hline & PG\&E & SCE & SDGE & $\begin{array}{c}\text { Direct } \\
\text { Access }\end{array}$ & MUD & $\begin{array}{c}\text { Irrigation } \\
\text { District }\end{array}$ \\
\hline Total & 29 & 4 & 2 & 1 & 2 & 5 \\
\hline DR Participant & 11 & 2 & 1 & 1 & 1 & 2 \\
\hline No DR Program & 18 & 2 & 1 & 0 & 1 & 3 \\
\hline
\end{tabular}

A total of 39 facilities reported whether they produce a portion of their consumed electricity on site. Of the 39 respondents, 13 reported generating electricity onsite, with some reporting more than one-generation method. Table 4 shows a breakdown of reporting facilities and the sources used to create electricity.

Table 4: Energy Used in On-Site Electricity Production

\begin{tabular}{|l|c|c|c|c|c|}
\hline & Biomass & Steam & Renewable & Diesel & Other \\
\hline Total & 3 & 1 & 6 & 2 & 4 \\
\hline DR Participant & 0 & 1 & 3 & 1 & 2 \\
\hline No DR Program & 3 & 0 & 3 & 1 & 2 \\
\hline
\end{tabular}




\section{DR Participants}

Questions tailored to the DR participating facilities inquired about their load shed ability, DR enrollment, and DR program type. The $15 \mathrm{DR}$ participating respondents combined for a peak demand reduction of $37.5 \mathrm{MW}$, averaging $2.5 \mathrm{MW}$ per facility. Four DR participating facilities are enrolled in a critical peak-pricing program, seven enrolled in a demand bidding program, one enrolled in a capacity bidding program, and none enrolled in a business energy coalition program. Nine DR participants use a third-party aggregator, while six facilities interacted directly with the vendor from which they purchase electricity.

\section{Variations in Electrical Demand}

The survey inquired about diurnal and seasonal variation in electricity demand. Of the 46 reporting facilities, 21 indicated diurnal increases in electricity consumption about 5 to 10 percent. Fifty-three percent (8/15) of DR participants and 42 percent (13/31) of non-DR facilities reported such variations in electricity use (see Figure C-8). Table 5 shows the percentage of facilities that reported elevated electricity demand during different times of the day. The most common increase in electricity demand occurred in the 2:00 pm to 4:00 pm time window. A larger fraction of DR participating facilities consistently have a higher rate of increased electricity consumption throughout the day, compared to non-DR facilities. The facilities with higher electricity demand may be targeted by utilities for DR participation.

Increases in electrical demand due to seasonal variation occur mostly during the months of May through October, California's summer (see Figure C-9). During this time, 20 respondents, 33 percent of DR participating facilities and 48 percent of facilities that are not participating in a DR program, reported increased electrical demand. The vast majority of reported seasonal variation occurs with fruit and vegetable producers, data centers, and water treatment facilities during summer (see Figure C-10). Few facilities reported increased electricity demand during the months of January to April (4) or November through December (3).

Table 5: Periods of Elevated Electricity Demand

\begin{tabular}{|l|c|c|c|c|c|}
\hline & $\begin{array}{c}8 \mathrm{am}-12 \mathrm{pm} \\
(\%)\end{array}$ & $\begin{array}{c}12 \mathrm{pm}-2 \mathrm{pm} \\
(\%)\end{array}$ & $\begin{array}{c}2 \mathrm{pm}-4 \mathrm{pm} \\
(\%)\end{array}$ & $\begin{array}{c}4 \mathrm{pm}-6 \mathrm{pm} \\
(\%)\end{array}$ & $\begin{array}{c}6 \mathrm{pm}-8 \mathrm{pm} \\
(\%)\end{array}$ \\
\hline Total & 48 & 67 & 71 & 67 & 43 \\
\hline DR Participant & 75 & 63 & 75 & 75 & 63 \\
\hline No DR Program & 31 & 69 & 69 & 62 & 31 \\
\hline
\end{tabular}

\section{Control Systems}

Out of 37 respondents, only three indicated that they did not have an EMCS or other industrial control system. Of the facilities using control systems, 30 of them (85 percent) had process control primarily semi- or fully automated (see Figure C-11). As seen in Table 6, the majority of respondents participating in demand response had fully automated processes, and vice-versa. All facilities had some sort of information technology or network security policy. Of the 34 facilities that reported using a control system, 22 indicated that they use it to record load data 
from their facility. DR participating facilities and non-DR facilities are equally likely to record load data.

Table 6: Process Control Classifications

\begin{tabular}{|l|c|c|c|}
\hline & $\begin{array}{c}\text { Manual } \\
(\%)\end{array}$ & $\begin{array}{c}\text { Semi-Automated } \\
(\%)\end{array}$ & $\begin{array}{c}\text { Fully Automated } \\
(\%)\end{array}$ \\
\hline Total & 12 & 47 & 38 \\
\hline DR Participant & 7 & 36 & 57 \\
\hline No DR Program & 16 & 59 & 25 \\
\hline
\end{tabular}

Thirty-four survey participants reported using a number of different vendors for their control systems needs. The various vendors are tabulated in Table 7 (see Figure C-12). A number of facilities reported using more than one vendor. The two most commonly used vendors are Allen Bradley and Invensys. Half of the reporting fruit and vegetable producers use a control system from Allen Bradley.

Table 7: Control System Vendor Used at Reporting Facilities

\begin{tabular}{|c|c|c|c|c|c|c|c|c|c|c|}
\hline & 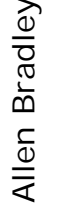 & 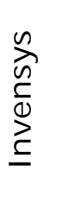 & 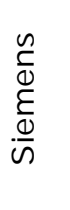 & 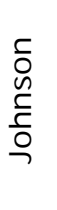 & 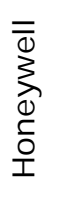 & 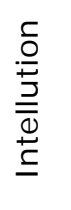 & 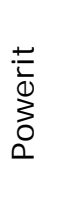 & 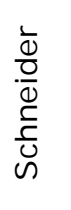 & $\frac{U}{4}$ & $\begin{array}{l}\frac{\pi}{0} \\
\frac{n}{n} \\
0\end{array}$ \\
\hline Total & 21 & 12 & 8 & 5 & 3 & 3 & 2 & 2 & 1 & 1 \\
\hline DR Participant & 8 & 7 & 2 & 1 & 2 & 1 & 1 & 1 & 1 & 0 \\
\hline No DR Program & 13 & 5 & 6 & 4 & 1 & 2 & 1 & 1 & 0 & 1 \\
\hline
\end{tabular}

Of the 34 facilities that reported using a control system, 12 indicated that the control system is used to manage individual end-use loads. Interestingly, a lower rate of DR participating facilities (28 percent) uses their control system to manage end-use loads than facilities not in a DR program (40 percent).

Centralized management of control networks is dominant in both DR participating facilities (7/10) and facilities with no DR program (12/13) (see Figure C-13). One DR participating facility and one facility with no DR program reported that a corporate network managed their control system. Additionally, two DR participants use an enterprise network to manage their control system.

A greater number of DR participants (9/14, 64 percent) utilize a centralized control of end-use loads, as compared to facilities that are not participating in a DR program (7/20, 35 percent). Of the 13 plants that are not in a DR program and do not centrally control end-use loads, five have plans to change to a central end-use control and eight have no such plans (see Figure C-14). 
Only one of the five DR participating facilities with no central end-use control has plans to switch to central control.

Out of 46 respondents, 34 facilities reported whether they use their control system to manage peak loads or not. Only 36 percent (5) of DR participants and 25 percent (5) non-DR participants reported using their control system to manage peak loads.

Thirty-three facilities reported whether their process control is fully, semi, or manually controlled (see Figure C-11). Fully or semi-automated process controls are seen as a key factor in the implementation of DR programs. Of the 33 reporting facilities, only four used only manual process controls. Out of the $14 \mathrm{DR}$ participating facilities that reported, only one used manual controls.

Of 13 facilities with networked controls not participating in a DR program, only one has their control system connected through the Internet. Within the group without Internet-connected controls, only one indicated that they plan to connect through the Internet in the future. Demand response participants are more likely to have their control system connected through the Internet, with 3 out of 10 respondents falling into this category.

\section{Respondent Production Characteristics}

Demand response readiness depends in part upon the production processes used at a facility. Survey questions regarding production characteristics were asked to establish what types of production processes are present in DR participating facilities and non-participating facilities.

Thirty of thirty-three respondents reported that they use a continuous production process opposed to a batch type process (see Figure C-15). Because of the interruptions to production caused by DR events, facilities that use batch type processes are assumed more receptive to DR acceptance. Contrary to this thinking, 16 out of the 19 DR participating facilities that reported production type use a continuous process, indicating that facilities using continuous processes may be good DR candidates.

In order for production sheds or shifts to have a measurable impact upon a facility's energy use, production must make up a significant portion of the facility's load. Eighty-five percent (33/39) of all respondents reported that production processes constitute at least 25 percent of the facilities peak load. This attribute is generic to both DR participating facilities and facilities with no DR program. Eighty percent (12/15) of DR participants and eighty-seven percent (21/24) of facilities with no DR program reported that production processes make up at least 25 percent of total facility peak load (see figures C-16 and C-17).

In order to participate in an Auto-DR program, production control systems with automatic shutdown ability are needed. Nine of 37 (24 percent) respondents indicated that their control system could be used to automatically shut down part of their process. Only 20 percent (3/15) of DR participating respondents indicated that their control system is capable of automatically shutting down production (see Figure C-18). It is not known from this study if the DR programs enrolled in are manual or automated. 


\section{Facility Audits}

Seventy-three percent (11/15) of DR participating facilities and 74 percent (17/23) of facilities with no DR program have had some form of energy audit. Table 8 shows the focus of the different audits, including: the entire facility, part of the facility, systems only, energy efficiency (EE) potential, and DR or Auto-DR potential. The average age of these audits was 1.6 years, with the oldest being four years old. It is not known if the audits conducted at DR participating facilities occurred before or after the implementation of their DR program.

Table 8: Focus of Energy Audits at Reporting Facilities

\begin{tabular}{|l|c|c|c|c|c|}
\hline & Full Facility & $\begin{array}{c}\text { Part of } \\
\text { Facility }\end{array}$ & Systems & EE Potential & $\begin{array}{c}\text { DR or Auto-DR } \\
\text { Potential }\end{array}$ \\
\hline Total & 20 & 4 & 6 & 7 & 7 \\
\hline DR Participant & 9 & 2 & 1 & 3 & 3 \\
\hline No DR Program & 11 & 2 & 5 & 4 & 4 \\
\hline
\end{tabular}

Of the 28 facilities that have had some form of energy audit (see figures C-19 and C-20), 18 reported whether the audit did or did not recognize a potential for DR implementation. Fiftyfive percent (10/18) of all facilities reported being identified as having DR potential. It is unknown whether the four of seven reporting facilities currently enrolled in a DR program and shown to have DR potential were audited before they enrolled in a DR program or if the audit led to the enrollment in a DR program.

\section{Decision Makers and Concerns about DR}

Survey respondents were asked about what person or persons in their organization would make the decision to participate in a DR program (Table 9). For both DR participating facilities and those with no DR program, the corporate manager was most commonly named as the position that would decide about DR participation. Facilities that already participate in a DR program indicated that the facility manager has almost equal decision-making potential as the corporate manager (see Figure C-21), which indicates that the company structure places a great deal of decision-making power at the level where the DR program will be implemented.

Following the facility manager, plant and production managers were evenly given decisionmaking power. Companies that are not participating in DR programs rely more heavily on their corporate managers to decide about DR participation. Following the decision-making power of the corporate manager is the plant manager. Lower-level management, such as the facility or production manager, has less decision-making power.

Table 9: DR Decision Makers

\begin{tabular}{|l|c|c|c|c|c|c|}
\hline & Corporate & Plant & Facility & Production & Maintenance & System \\
\hline Total & 25 & 19 & 14 & 10 & 5 & 3 \\
\hline DR Participant & 9 & 6 & 8 & 6 & 2 & 1 \\
& $(28 \%)$ & $(19 \%)$ & $(25 \%)$ & $(19 \%)$ & $(6 \%)$ & $(3 \%)$ \\
\hline
\end{tabular}




\begin{tabular}{|c|c|c|c|c|c|c|}
\hline No DR Program & $\begin{array}{c}16 \\
(36 \%)\end{array}$ & $\begin{array}{c}13 \\
(29 \%)\end{array}$ & $\begin{array}{c}6 \\
(14 \%)\end{array}$ & $(10 \%)$ & $\begin{array}{c}3 \\
(7 \%)\end{array}$ & $(4 \%)$ \\
\hline
\end{tabular}

Both DR participating facilities and non-DR facilities were asked about perceived barriers to DR participation. The largest perceived barriers towards DR participation are the assumed lack of ability to shed or shift loads (20 respondents) and risks to production ( 21 respondents). It is speculated that many facilities may not understand their potential to shed or shift load and that DR audits may decrease this barrier. Surprisingly, concerns about financing the transition to DR participation were low (10 respondents). No respondents indicated that there is a concern about a need to restructure their operation due to DR participation (see Figure C-22).

\section{Desired Features/Benefits in DR Participation}

A series of questions in the survey asked about which features of an Auto-DR program would provide the highest value to the facility. As shown in Table 10, the responses were given on a 1to-10 scale, with "1" indicating no value added (see Figure C-23). Fourteen DR participants and 21 facilities without a DR program responded to these questions. Highlighted values indicate areas of difference between DR participating facilities and non-DR facilities. 
Table 10: Preferred Features for Auto-DR Program

\begin{tabular}{|l|c|c|}
\hline & $\begin{array}{c}\text { DR } \\
\text { Participating }\end{array}$ & $\begin{array}{c}\text { No DR } \\
\text { Program }\end{array}$ \\
\hline $\begin{array}{l}\text { Access to real-time pricing } \\
\text { information }\end{array}$ & 4.9 & 5.9 \\
\hline Increase in end-use metering & 4.9 & 5.2 \\
\hline $\begin{array}{l}\text { Advanced agreement on DR } \\
\text { black-out dates }\end{array}$ & 4.6 & 4.7 \\
\hline $\begin{array}{l}\text { Value added services (DR opt-out } \\
\text { capacity, 24 hr. in advanced } \\
\text { notification, etc.) }\end{array}$ & 4.4 & 4.6 \\
\hline Feedback on DR participation & 3.9 & 5.0 \\
\hline $\begin{array}{l}\text { Ease of management and } \\
\text { participation }\end{array}$ & 3.9 & 4.3 \\
\hline $\begin{array}{l}\text { Incentives to upgrade facility } \\
\text { controls }\end{array}$ & 2.6 & 3.9 \\
\hline $\begin{array}{l}\text { Increased reliability of service } \\
\text { through automation }\end{array}$ & 4.0 & 3.5 \\
\hline $\begin{array}{l}\text { Favorable electricity tariffs and } \\
\text { credits for participation }\end{array}$ & & \\
\hline
\end{tabular}

Features with greatest perceived benefit include access to real-time pricing, increase in end-use metering, value-added services, and advanced agreements on DR blackout dates. Participants in DR programs were more interested in favorable electricity tariffs than non-DR facilities, presumably because they already have made the switch to DR and want their actions to result in a financial incentive. Non-DR facilities were more interested in increased reliability of service through automation and feedback about DR participation as compared to DR participants.

\subsection{Conclusions Drawn from Survey Responses}

The 46 valid industrial survey responses represent a wide range of industrial sectors in California. The responses allow for aggregated analysis comparing DR participants to facilities that do not participate in a DR program.

Comparisons between facilities with and without DR programs show technical and operational similarities. This indicates that facilities not participating in a DR have potential for DR participation. 
Demand response facilities and non-DR facilities have similar diurnal and seasonal increases in electrical demand. Both types of facilities show increased electrical demand during the midafternoon ( $2 \mathrm{pm}-4 \mathrm{pm})$. Additionally, both types of facilities use far more energy during the summer months, May through October.

Similar production processes are used in DR and non-DR facilities. The vast majority of both types of facility have processes that consume greater than 25 percent of the total electricity demand. This high amount of facility demand going towards processes indicates large amounts of shed/shift potential if the process is interruptible. Batch processes are generally thought to be interruptible compared to continuous processes. However, the vast majority of both DR and non-DR facilities use a continuous process system, but this does not preclude them from participating in DR.

Demand response and non-DR facilities both utilize fully or semi-automatic controls at a higher rate than manual controls. These automated controls are precursors to the implementation of Auto-DR. Management of control systems is most commonly performed at a central facility level, not at a corporate or enterprise level, for both DR and non-DR facilities. Only about 24 percent of facilities use automatic controls with shutdown capabilities, which is a precursor to Auto-DR participation.

Operationally, DR and non-DR facilities both participate in some form of energy audit at the same rate. However, these audits typically do not focus on DR or Auto-DR potential. For both types of facilities, finances are not the biggest barriers to DR participation; the biggest barrier is the inability to shed/shift load or an adversity to production risk. Audits targeting DR and Auto-DR potential may indicate shed/shift load capability and relieve some of these barriers.

Demand response facilities and non-DR facilities differ technically and operationally in some factors. Facilities participating in a DR program are more likely to have control systems that are used in conjunction with end-use loads than non-DR facilities. Control of end-use loads is a major enabler of DR participation to shed large process loads. Operational decisions about DR participation are made at different levels within a company for DR and non-DR facilities. NonDR facilities place more decision-making power in the hands of corporate leaders who might be distant from the technical potential for DR at the facilities. Demand response participants still rely upon corporate-level management, but also enable their plant and facility managers to participate in DR decisions.

\subsection{Results Integrated with Other Sources}

To ascertain the validity of results from analysis of survey responses, data from a brewery were cross-referenced with data collected from other sources (e.g., integrated audits, fieldwork, and sector-based analyses). The results matched well.

Based on controls survey responses from the facility, and corroborated by electric demand trends from May 2008, the facility is not normally subject to wide swings in electric usage over the course of the day. The average whole-day demand of 7,619 $\mathrm{kW}$ was essentially the same as the 9 am to $6 \mathrm{pm}$ demand of $7,645 \mathrm{~kW}$ ), and it does not experience wide swings from day to 
day. The plant's survey responses also indicate that it is equipped with a fully automated control system, with centralized control of processes, operations, and packaging; has at least 10 electric meters; and is participating in DR. A year later, in May 2009, the facility was audited for DR potential. The plant attempted to reduce baseline electric consumption by means of energy efficiency measures, as well as shift load away from the daytime grid peak period from 9 am to 6 pm. Averaged data from May 2009 is presented below.

- 9 pm to 6 am: Electric demand is 7,007 kW, which is $588 \mathrm{~kW}$ less than the 7,595 kW demand during same time of day in May 2008. Not adjusting for consumer demand or weather variation, this could be attributable to various energy efficiency measures that were implemented.

- 9 am to 6 pm: After gradual ramp down from 6 am to 9 am, electric demand is maintained at average of $6,176 \mathrm{~kW}$ from 9 am to $6 \mathrm{pm}$, and then is ramped back up during the period from $6 \mathrm{pm}$ to $9 \mathrm{pm}$. This is sustained reduction of $831 \mathrm{~kW}$, or 12 percent over a relatively long nine-hour period. Considering that most DR events last for only two to four hours, this is indicative of a reasonable day-ahead DR potential, subject to further operational modifications.

The results of the demand reductions align with the DR characterization framework. The large, steady loads; electric metering; and advanced control system capabilities all suggest good potential for DR, and the permanent load shifts and participation in a DR program agree with the framework's suggestion.

\subsection{Feedback from the Control Experts Group}

Lawrence Berkeley National Laboratory conducted meetings and workshops with eleven select industrial control systems experts and thought leaders, to present the preliminary findings for review and solicit feedback. The purpose was to validate or refine findings and to obtain input on industrial sectors that may be good candidates for DR studies. Discussion at the meeting identified the need to break large industrial sectors down further to accurately assess DR potential (e.g., the dairy industry includes manufacture of milk, cheese, ice cream, and other products, all of which have different process characteristics).

As a follow-up to the meeting, a feedback form was sent to meeting participants to assess the DR potential of various industry subsectors with assumed DR potential. Appendix E shows the feedback form. As with the survey, the feedback form was mostly comprised of multiple-choice questions for ease of data collection and processing. Most of the questions were adapted from the survey, and others were added based on discussions during and after the meeting. The participants were also asked to rate the technical, operational, and overall DR potential of each subsector. Six participants returned the form, yielding 19 sector-specific evaluations spanning 14 industrial subsectors.

The resulting evaluation and feedback verified many of the findings of the DR characterization framework. Higher ratings of hour-to-hour prediction and interruptions were correlated with higher operational DR potential. Sectors with energy management decisions concentrated at the 
corporate level were rated as having less overall DR potential than the sectors with more distributed decision-making. Higher ratings of both energy efficiency and DR history correlated with higher overall DR potential. Unsurprisingly, higher ratings of technical and operational DR potential were correlated with higher overall DR potential.

Previous DRRC work identified Wastewater Treatment, Refrigerated Warehouses, and Data Centers as worthy of detailed DR study. Based on the results of the feedback forms, several new subsectors have been suggested as having possible DR potential. These suggestions were based on frequency of recommendation, overall DR potential, and past DR participation. The suggested subsectors are Tortilla Manufacturing, Wineries, Ice Cream and Frozen Dessert Manufacturing, and Cheese Manufacturing. Of these, all but Ice Cream and Frozen Dessert Manufacturing have had case studies published detailing DR activities (EnerNOC 2008, 2009; PG\&E 2006). The annual energy consumption for each industry is shown in Table 11.

Table 11: Annual Electricity Consumption for Subsectors with Suggested DR Potential

\begin{tabular}{|l|c|c|}
\hline \multirow{2}{*}{\multicolumn{1}{|c|}{ Industry }} & \multicolumn{2}{c|}{ Electricity consumption (million kWh) } \\
\cline { 2 - 3 } & 2009 & 2010 \\
\hline Cheese Manufacturing & 451 & 503 \\
\hline $\begin{array}{l}\text { Ice Cream and Frozen Dessert } \\
\text { Manufacturing }\end{array}$ & 188 & 180 \\
\hline Tortilla Manufacturing & 101 & 100 \\
\hline Wineries & 794 & 619 \\
\hline
\end{tabular}




\section{CHAPTER 5: Conclusions}

The vast majority of facilities surveyed have either fully or semi-automated control systems in place, indicating that they have technical capability for either fully or semi-automated DR programs. Furthermore, a majority of facilities with fully automated process control were DR participants, reinforcing the link between advanced controls capabilities and DR participation. The most common perceived barrier to DR participation was lack of ability to shed or shift, followed by risk to production processes. Interestingly, very few facilities were concerned about financial incentives. This suggests that demonstrating the feasibility of DR strategies that are proven to cause no impact to production can increase DR participation.

Results from the survey responses and control experts' feedback reinforce the assumption that there are industry characteristics that support DR participation. Characteristics found to be conducive to DR potential are advanced control systems, high-energy use, predictable loads, a history of energy efficiency measures, and participation in energy decision-making by production and facilities managers.

The controls survey response size, while not large enough to be considered statistically significant, identified the broad characteristics of DR-compliant sectors that were consistent across the majority of responses. These broad characteristics, while serving to qualify or exclude certain sectors, did not cover the nuances of the subsectors within a sector where suitability for DR may vary. Expert recommendations guided the identification of wastewater treatment, wineries, tortilla manufacturing, and dairy product manufacturing (specifically ice cream and cheese) as sectors and subsectors with a large DR potential.

\subsection{Next Steps}

Although many facilities have the physical capability to participate in Auto-DR, perceived barriers hamper participation. Activities to dispel these negative perceptions could include the following:

- In-depth analysis of industrial facilities that have fully or semi-automated controls to demonstrate Auto-DR - with a focus on technologies, feedback controls, and information needed to receive and respond to dynamic pricing signals - can show that barriers to DR participation are not as high as perceived. This will also help identify specific DR shed or shift strategies through case study demonstrations and counter perceived risks to production processes, thus accelerating the market for industrial sector participation.

- Further investigating industrial sectors suggested of having inherent DR potential, to increase awareness throughout California industry.

- Increasing the scope of the controls analysis. The existing data set is insufficiently comprehensive to make generalized recommendations across California industries. More data and reporting of detailed analysis are necessary to aid California's dynamic pricing 
policies for the industrial sector. Alternative methods of obtaining these data can include working with controls equipment vendors or third-party energy consulting companies.

- The low level of respondents indicates the need for training and outreach to the industrial facilities that will lead to a better understanding of the value of DR. 


\section{References}

EnerNOC, Inc. 2008. Cabot Creamery makes demand response a critical part of its environmental stewardship.

$<$ http://www.enernoc.com/pdf/testimonials/businesses/cabot-creamery.pdf $>$.

EnerNOC, Inc. 2009. EnerNOC DR helps growing food business cook up new energy savings. <http://www.enernoc.com/resources/files/cs-albuq-web.pdf>.

Ghatikar, G., M. A. Piette, S. Fujita, A. McKane, J. H. Dudley, A. Radspieler (Lawrence Berkeley National Laboratory); K. C. Mares (Megawatt Consulting); D. Shroyer. 2010. Demand Response and Open Automated Demand Response Opportunities for Data Centers. Berkeley, California. LBNL-3047E. January.

Katipamula, S., and S. Gaines. 2003. Characterization of Building Controls and Energy Efficiency Options Using Commercial Building Energy Consumption Survey. PNWD-3247. February.

Kiliccote, S., M. A Piette, J. Mathieu, and K. Parrish. 2010. Findings from Seven Years of Field Performance Data for Automated Demand Response in Commercial Buildings. LBNL-3643E.

Lekov, A., L. Thompson, A. McKane, A. Rockoff, and M. A. Piette. 2009a. Opportunities for Energy Efficiency and Automated Demand Response in Industrial Refrigerated Warehouses in California. LBNL-1991E. May.

Lekov, A., L. Thompson, A. McKane, K. Song, and M. A. Piette. 2009b. Opportunities for Energy Efficiency and Open Automated Demand Response in Wastewater Treatment Facilities in California - Phase I Report. LBNL-2572E. April

McKane, A. T., M. A. Piette, D. Faulkner, G. Ghatikar, A. Radspieler Jr., B. Adesola, S. Murtishaw, and S. Kiliccote. 2008. Opportunities, Barriers and Actions for Industrial Demand Response in California. LBNL-1335E. January.

McKane, A., I. Rhyne, A. Lekov, L. Thompson, and M. A. Piette. 2008. “Automated Demand Response: The Missing Link in the Electricity Value Chain." 2008. ACEEE Summer Study on Energy Efficiency in Buildings, Pacific Grove, California, 2008. LBNL-2736E.

Pacific Gas \& Electric Company. 2006. E. \& J. Gallo Winery. Case study. $<$ http://www.pge.com/includes/docs/pdfs/mybusiness/energysavingsrebates/demandres ponse/cs/Wineries_Gallo_Integrated_CaseStudy.pdf>.

Piette, M. A., S. Kiliccote, and G. Ghatikar. October 2009. Design and Implementation of an Open, Interoperable Automated Demand Response Infrastructure. October 2007. Presented at the Grid Interop Forum, Albuquerque, New Mexico, November 7-9, 2007. LBNL-63665.

Piette, M. A., G. Ghatikar, S. Kiliccote, E. Koch, D. Hennage, P. Palensky, and C. McParland. 2009. Open Automated Demand Response Communications Specification (Version 1.0). California Energy Commission, PIER Program. CEC-500-2009-063 and LBNL-1779E. 
Thompson, L., A. Lekov, A. McKane, and M. A. Piette. August 2010. Opportunities for Open Automated Demand Response in Wastewater Treatment Facilities in California - Phase II Report: San Luis Rey Wastewater Treatment Plant Case Study. LBNL-3889E. 


\section{Appendix A \\ Common Types of Controls and Terminology}

Industrial controls include systems and configurations (sometimes integrated) to manage process loads, utilities such as compressed air and steam, local operations, building systems, and business systems. Examples of such Energy Management Control Systems (EMCS) and configurations are Supervisory Control and Data Acquisition Systems (SCADA), Programmable Logic Controllers (PLC), and Distributed Control Systems (DCS). These classes of EMCS in industrial use are vary in definition and the functions they perform

SCADA (Supervisory Control and Data Acquisition) systems are implemented using a design philosophy that integrates independent controllers in an essentially open loop control system. SCADA presents process information, operating parameters, alarms, and reports, to human operators who supervise and control the process through a HMI (Human Machine Interface).

DCS (Distributed Control System) is implemented using a design philosophy of total factory or process automation operating under a common closed loop control system. DCS is integrated at a factory wide production level including alarming, recording, closed loop control and monitoring with an integrated graphical front end HMI (Human Machine Interface). The scope of SCADA and DCS often overlap, and some of the common components in both are microcomputers, instrumentation, control equipment and software.

PLC (Programmable Logic Controller) is a digital computer microprocessor control used for industrial process and machine automation. PLC's are general-purpose controllers designed to adapt a wide range in input and output channels to a variety of control applications. A PLC's electrical circuitry, power supply, and enclosure are designed for the rigors of an industrial environment including operation at elevated temperature, power instability, and mechanical shock or vibration. Original PLC equipment primarily used digital I/O (inputs and outputs) programmed using ladder logic diagramming software. Over time PLC's incorporated support for analog I/O and programming environments allowing analog feedback control and PID (Proportional, Integral, Derivative) loop control.

Microcontroller is a digital computing device designed and programmed to accomplish a specific control function where there is no requirement to significantly alter its function once final design, testing and debugging is complete. Support for digital and/or analog input/output $(\mathrm{I} / \mathrm{O})$ is implemented as necessary with little or no provision for future I/O flexibility. Digital Process Controllers are best suited for applications where thousands of identical units will be produced to perform identical or a limited range of variations in function.

Digital Process Control is a generic term which has traditionally referred to an electronic control device with only digital input / output capability. The term has also come to be used to describe any type of digital computing device used in process control, which may have digital 
and / or analog I/O capability. Also a general term applied to control methods that use digital computing as component of process control.

RTU (Remote Terminal Unit) is primarily a "Slave" interface device between a "Master" digital computer performing process control or data acquisition and field devices such as operating valves, actuators, and transducers. The RTU is equipped with one or more communication interface used to transmit and receive operating messages. Some RTU devices have internal processing power to perform simple operating instructions, and data acquisition during periods of time when communication to the "Master" is interrupted.

Communication Interface is a connection, which allows the exchange of information between two or more digital computers or peripheral devices. Communication interfaces are comprised of two components; a physical layer and a communication protocol.

Communication Physical Layer is the physical interconnection between the digital computers and/or peripheral devices. For example electrical wiring and connectors, radio transmitter / receiver, or infrared transmitter / receiver, etc. create a "physical" connection between devices. The physical layer carries signals between devices. Common communication interface standards include specified wired connections such as RS232, RS422, RS485, Ethernet, etc.; and the characteristics of electrical signals that pass through the connection. A wireless physical layer such as IEEE 802.11 is a set of standards for wireless local area network (WLAN), which specifies over-the-air modulation techniques, and the segment of radio frequency spectrum used.

Communication Protocol Layer is the definition of messages that are passed between devices. Protocol standards define the exact sequence of bits, characters, and control codes used to transfer data between computers and peripherals through a communications interface. Protocols may be "open" with publically available message structure; or "closed" where in the manufacturer does not publicly disclose the message structure. Communication protocol data layer i.e. Modbus, TCP/IP, FTP, IPX/SPX, Factory Talk, BACnet, etc.

HMI (Human Machine Interface) encompasses all of the devices and means by which people (operators) interact with a machine or process system. In the simplest form a "RUN / STOP" switch is an HMI. Expanding that interface might include a "power on" light and "running" light to give the operator additional information about the status of the machine. Normally in the field of industrial control automation an HMI is more advanced and might include a touch screen or computer, which provides the operator with many indications of real time performance for the machine or process. The HMI may also provide the operator with access to many different controls used to adjust performance. The HMI may give the operatory advisory and / or fault alarms alerting the operator to the need for maintenance or repair.

Peak Load Management (PLM) includes facility measures that are undertaken on daily bases to reduce electricity use demand charges during on-peak times by either curtailing electricity use or shifting during off-peak times. Peak load management strategies include modification of 
behavior to regulate energy consumption by using facility control systems for a specific time, day, season, etc.

Demand Limiting measures are used within a facility to maintain electricity loads by implementing strategies either manually or using control systems to manage usage below a determined upper demand limit for a specific time, day, season, etc. 


\section{Appendix B \\ Open Automated Demand Response (OpenADR) Technology Overview}

The technology used for OpenADR programs for industrial facilities in 2007 originated from initial conceptual design in 2002 at LBNL to support open standards-based data models to communicate price and reliability DR events. OpenADR is a fully automated demand response system using Client/Server based service oriented architecture (SOA) and is intended to replace labor-intensive manual and semi-automated DR. Before 2007, Auto-DR was primarily used for commercial buildings for HVAC and lighting end-use loads using signals between utilities and customer facilities based on communication technology standards that integrated with thirdparty proprietary controls and communications software. The essential elements of an OpenADR system are shown in Figure 1 and include:

- Demand Response Automation Server (DRAS) for Auto-DR based on the interoperable, standard-based architecture using Web Services (WS);

- Client \& Logic with Integrated Relay (CLIR) box, WS software client, etc., customized for industry requirements, providing flexibility for participation; and

- Energy Management Control Systems, Energy Information Systems (EMCS/EIS) or other forms of control systems with pre-programmed DR strategies are used within the industry.

OpenADR systems are built using secure Web Service for platform-independent; interoperable systems that use low-bandwidth secure Internet connections. This OpenADR technology has been used for Pacific Gas and Electric Company's (PG\&E) and Southern California Edison's (SCE) Critical Peak Pricing (CPP) and/or Demand Bidding Program (DBP) Auto-DR programs during 2007-09 and can be scaled to accommodate California's goal of dynamic-pricing and real-time-pricing (RTP) models. As shown in Figure B1, the steps involved in the OpenADR process during a DR event are:

1. The Utility or ISO defines DR event and price signals are sent to the DRAS;

2. DR event and price services published on the DRAS;

3. DRAS Clients (CLIR or WS) request real-time event data from the DRAS every minute;

4. Customized pre-programmed DR strategies determine action based on event price/mode;

5. Facility Energy Management Control Systems (EMCS) or related controls carry out load reduction based on DR event signals and strategies. 


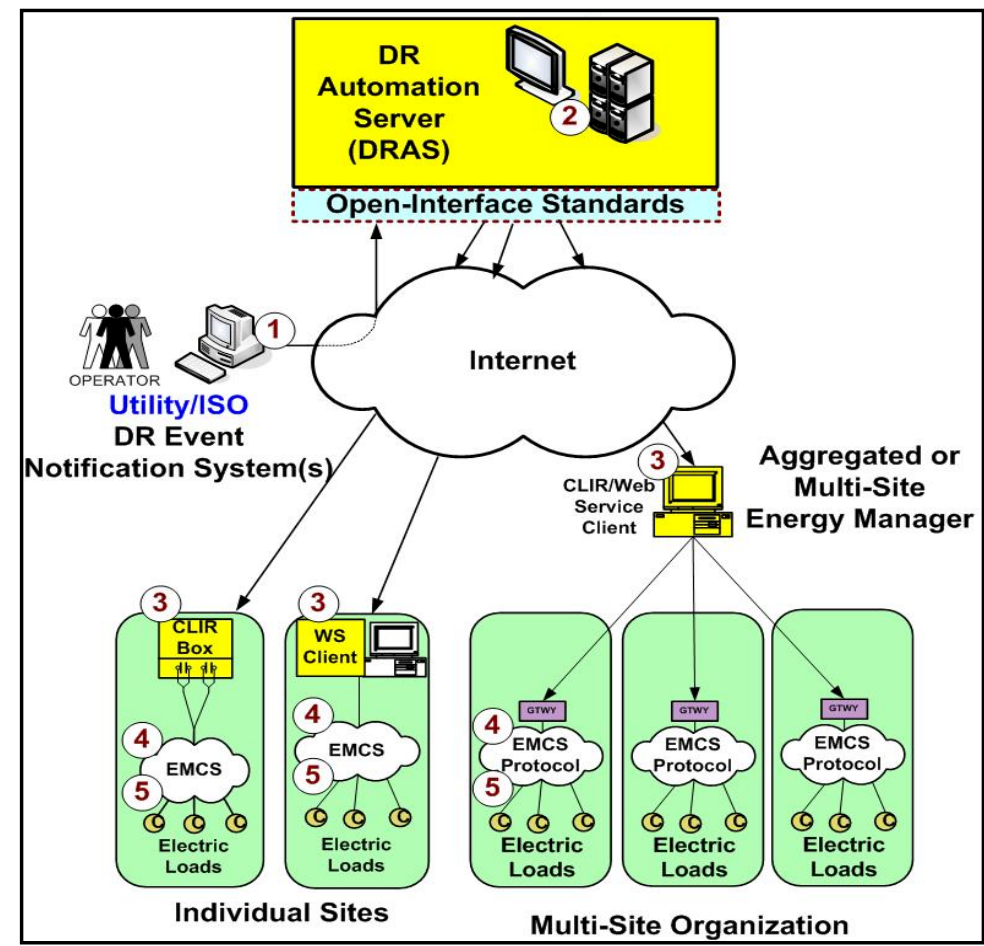

Figure B1: OpenADR Technology and Communication Architecture 


\section{Appendix C \\ Graphical Representations of Survey Results}

These figures reference Section 4.2.

Figure C-1: 46 Valid Survey Respondents by Industrial Sector

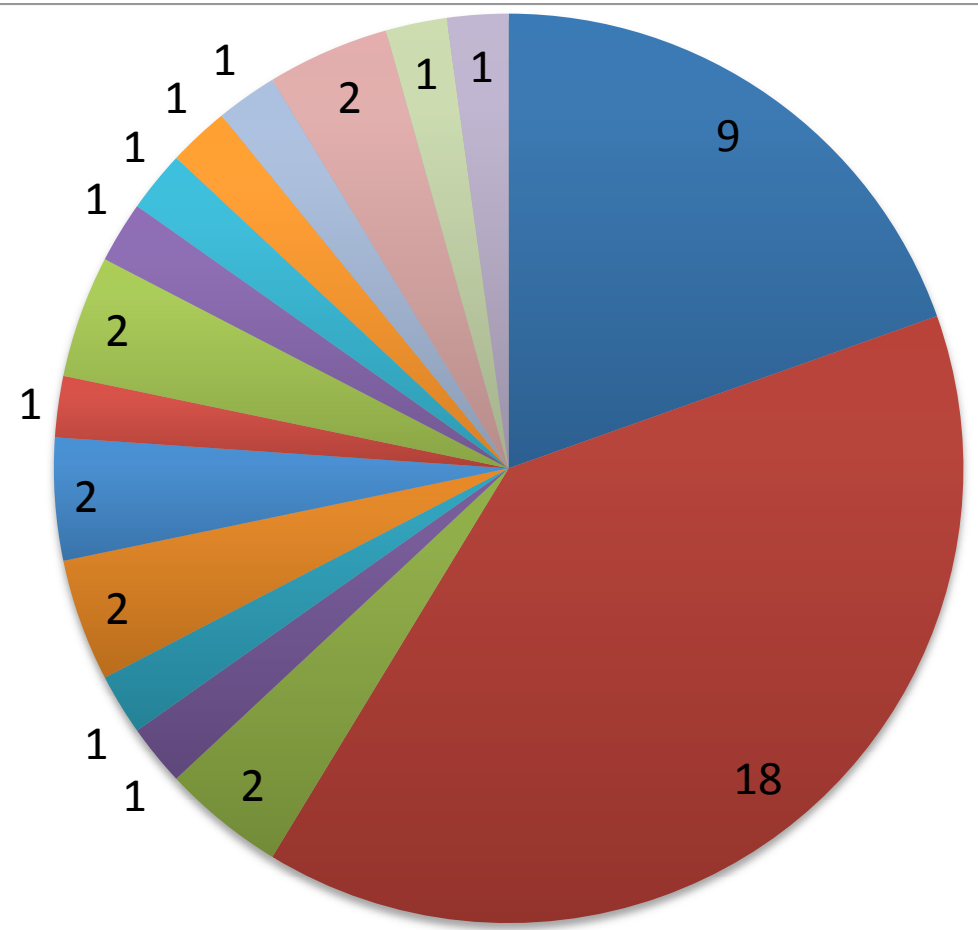

2213 - Water-Wastewater Treatment

3114 - Fruit and Vegetable Processing

3121 - Beverages

3241 - Petroleum/Coal

3254 - Pharmaceuticals/Medicine

3272 - Glass

3273 - Cement and Concrete

3274 - Gypsum

3344 - Semiconductor/Electronics

3363 - Motor Vehicle Parts

4869 - Petroleum Transportation

4881 - Airport

4931 - Warehousing and Storage

5182 - Data Centers 
Figure C-2: 46 Valid Survey Respondents with and without DR Programs

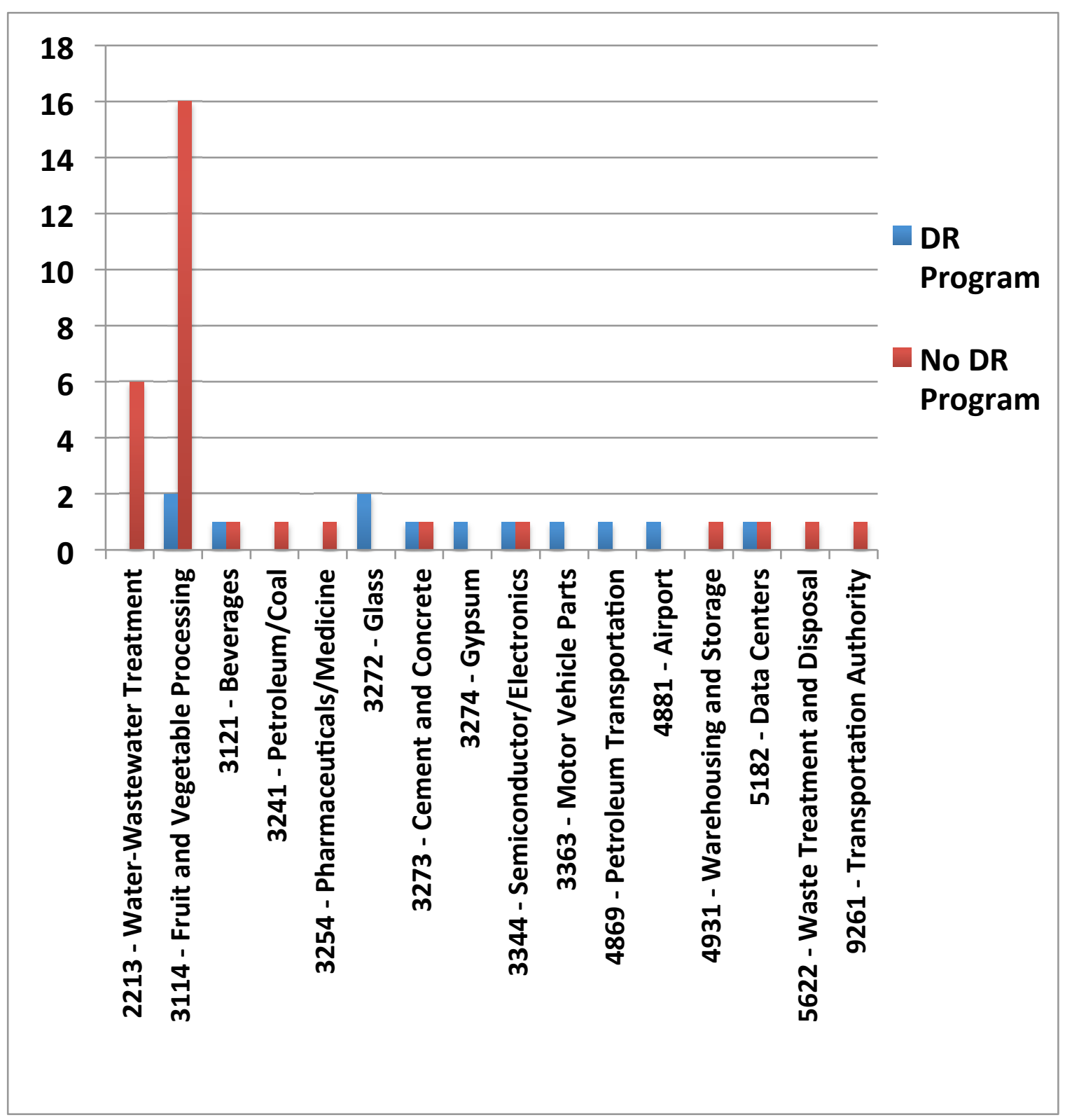


Figure C-3: Percentage of Survey Respondents with and without DR Programs

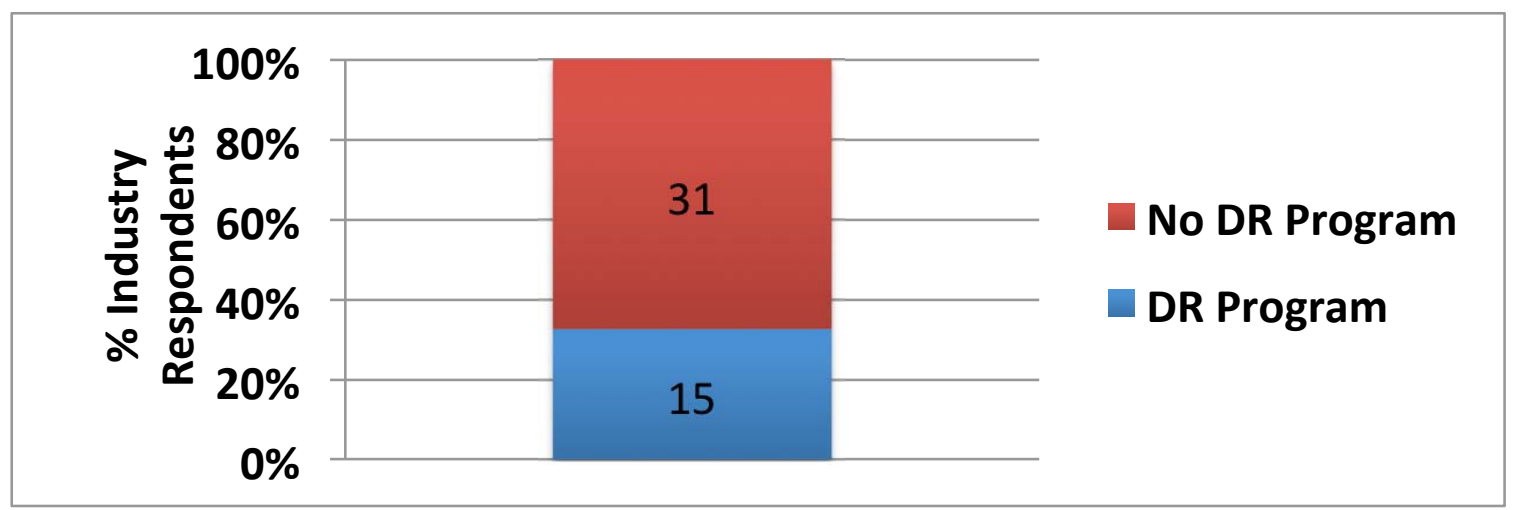

Figure C-4: Electrical Demand Profile of Survey Respondents

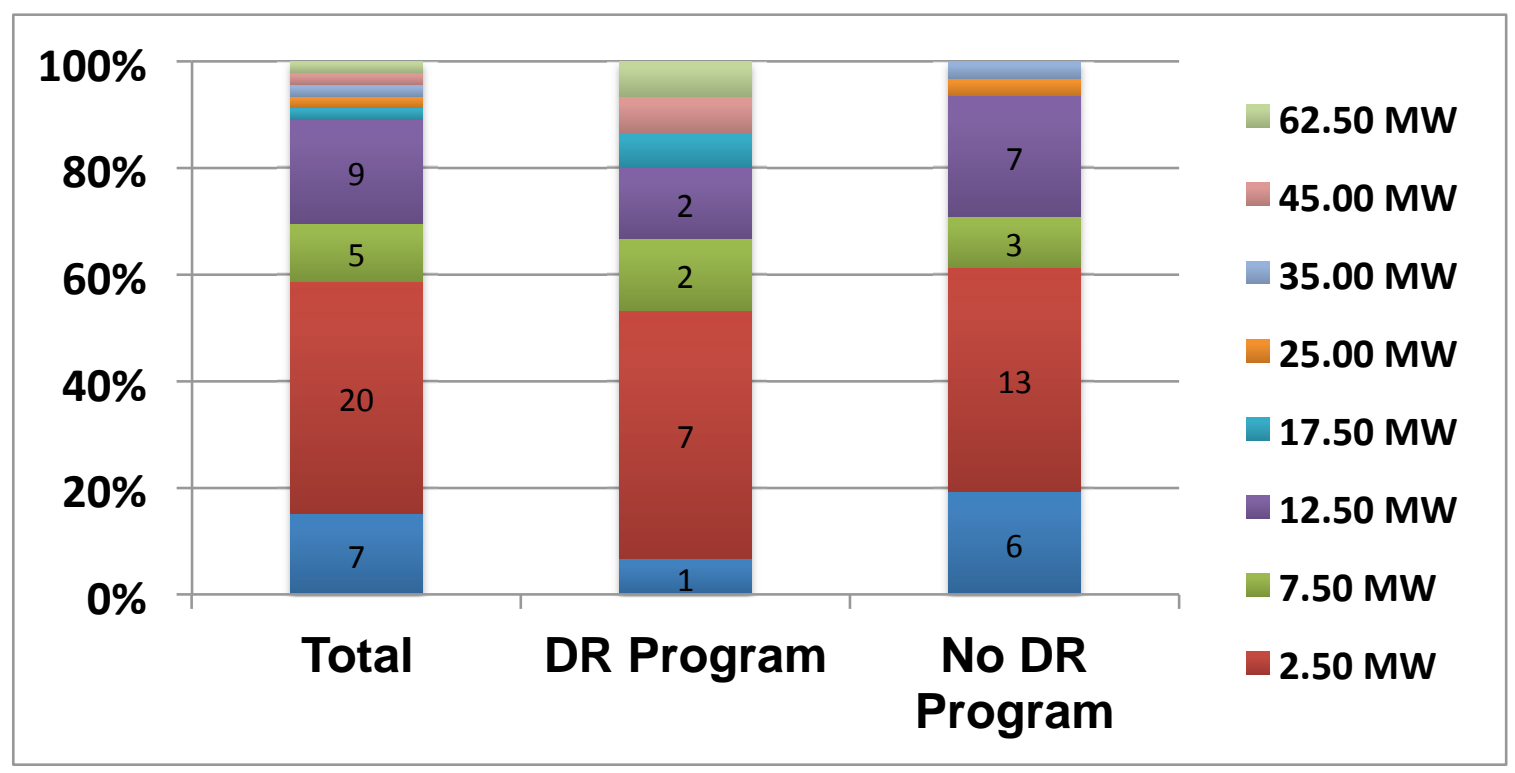


Figure C-5: Peak Electrical Demand by Survey Respondents

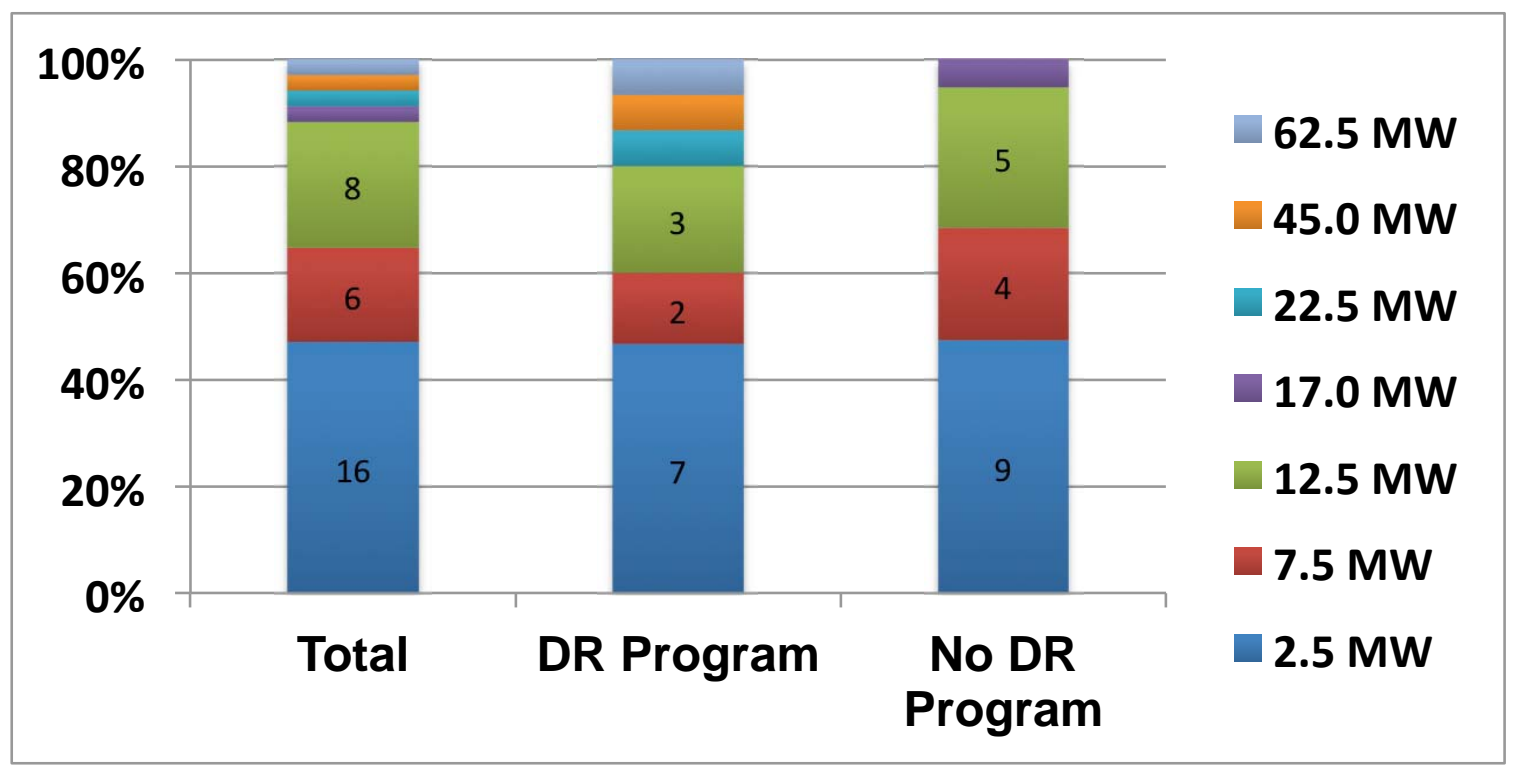

Figure C-6: Annual Survey Respondent Expenditures on Electricity

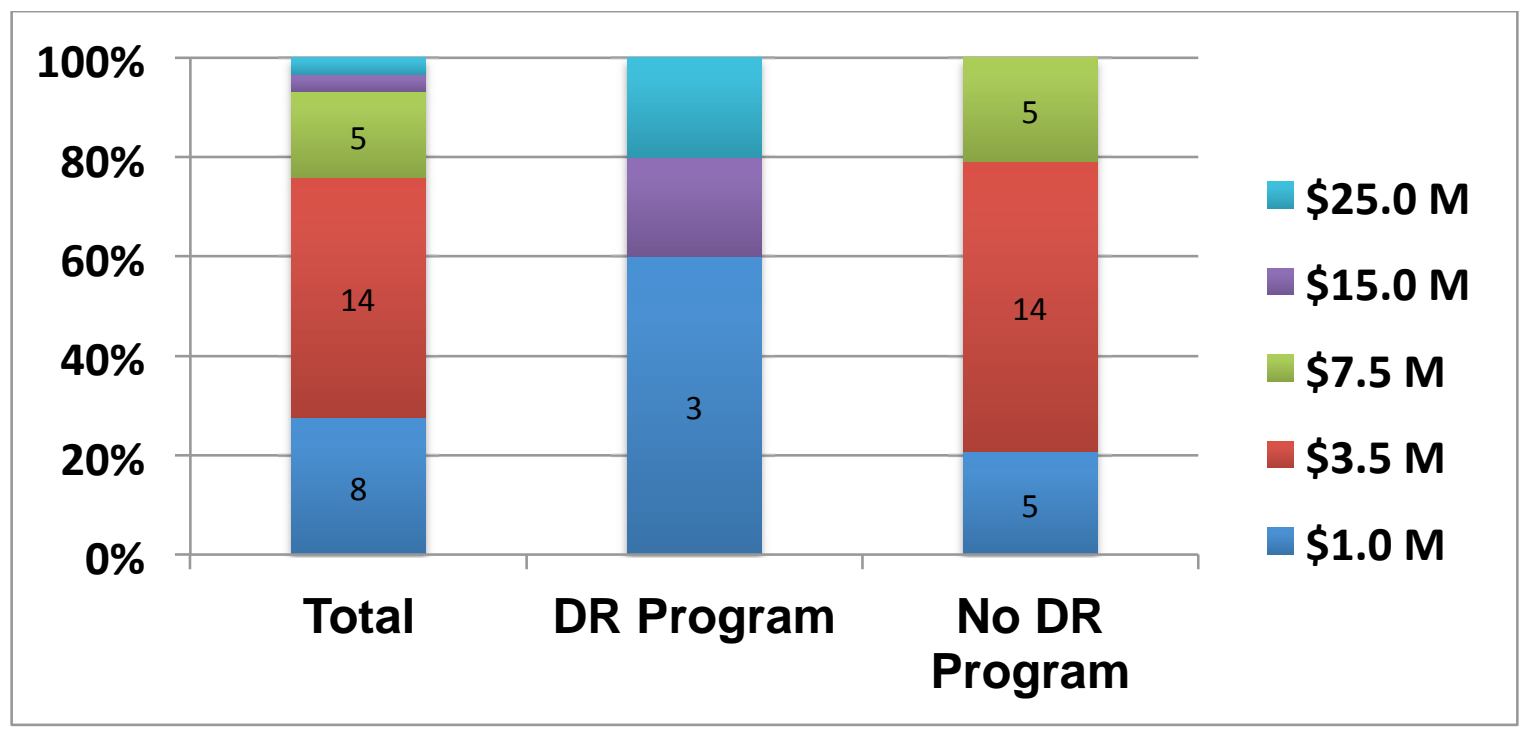


Figure C-7: Vendor of Purchased Electricity

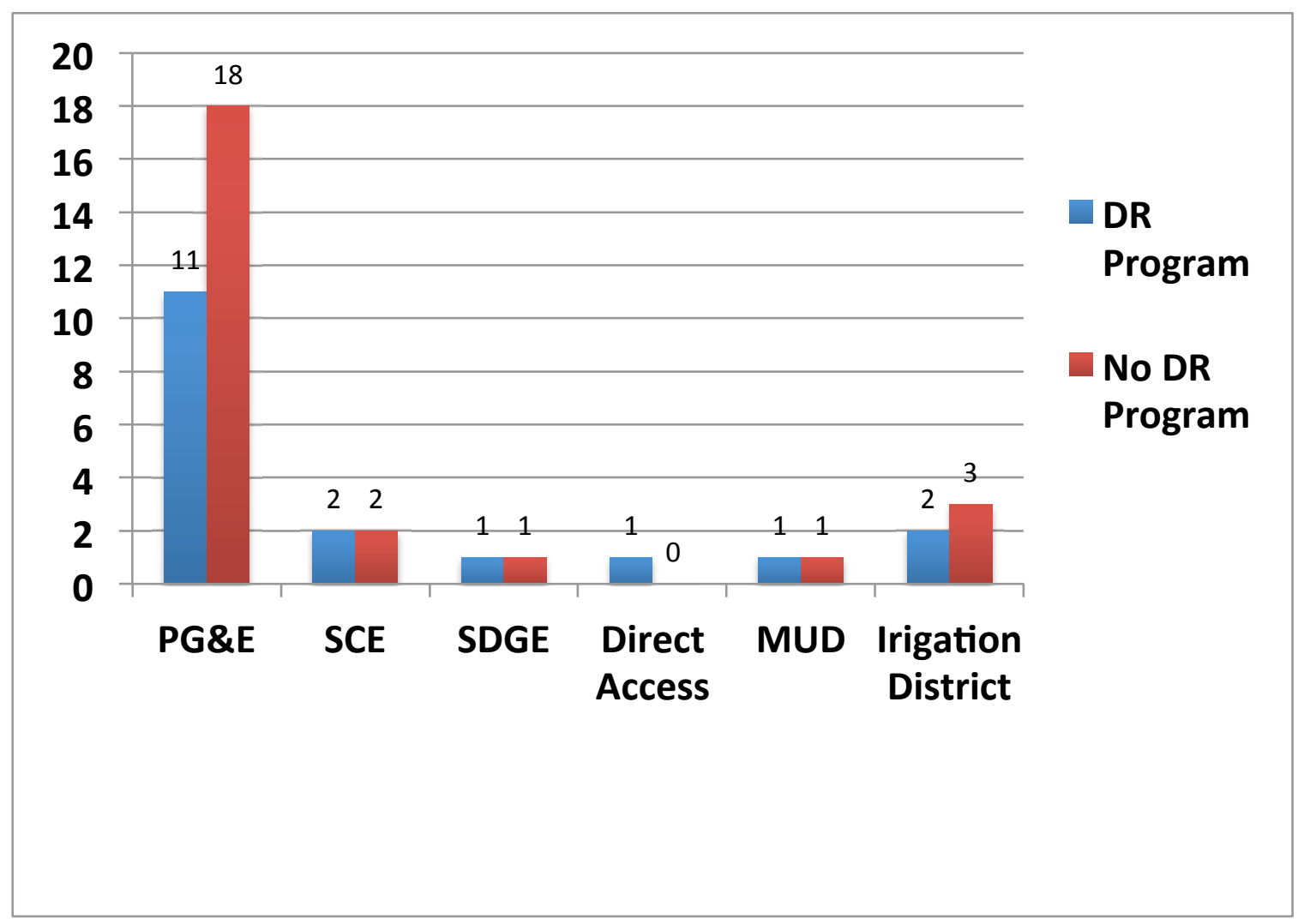

C-5 
Figure C-8: Diurnal Variations in Electricity Demand

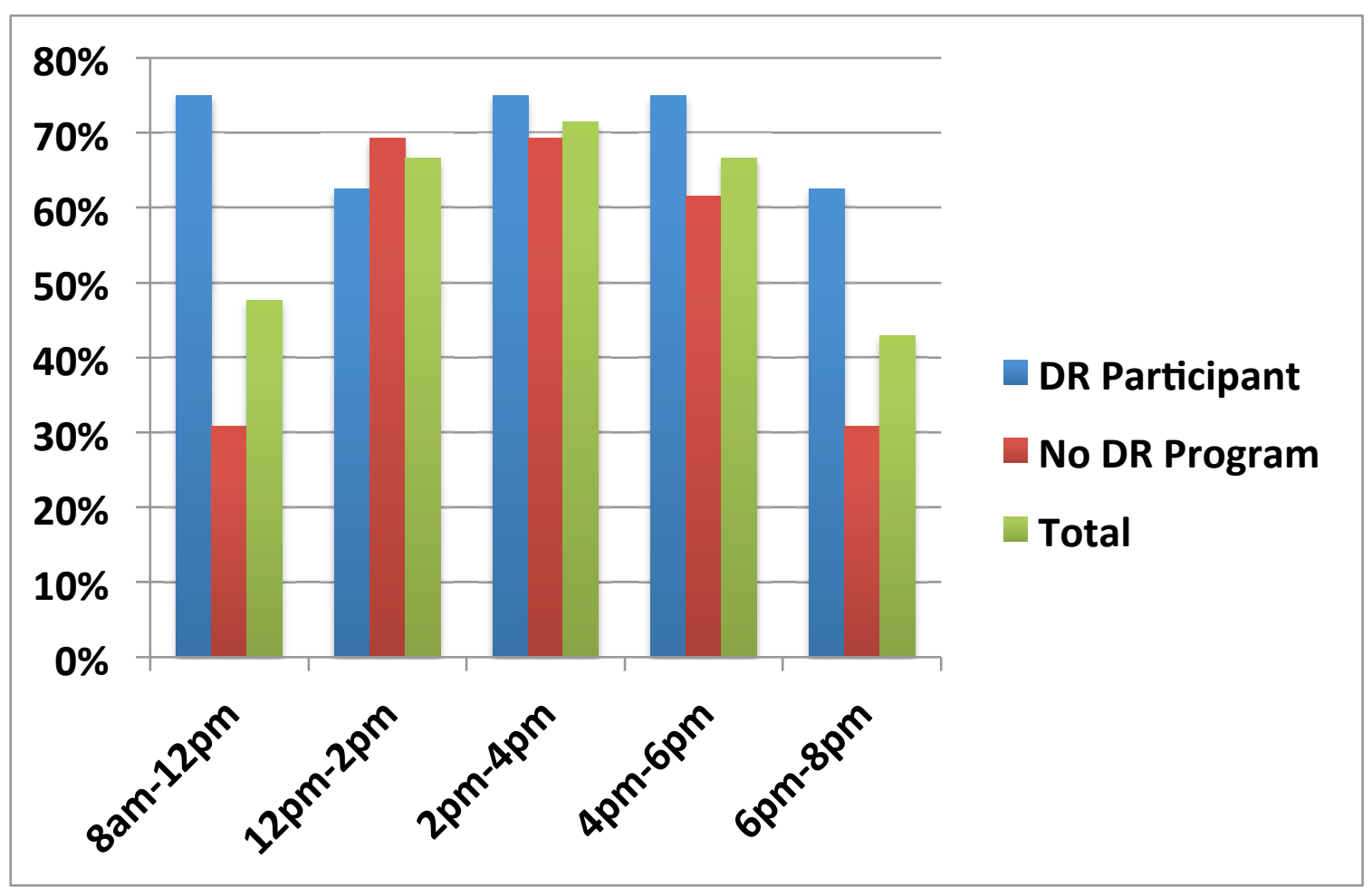

Figure C-9: Seasonal Variations in Electricity Demand

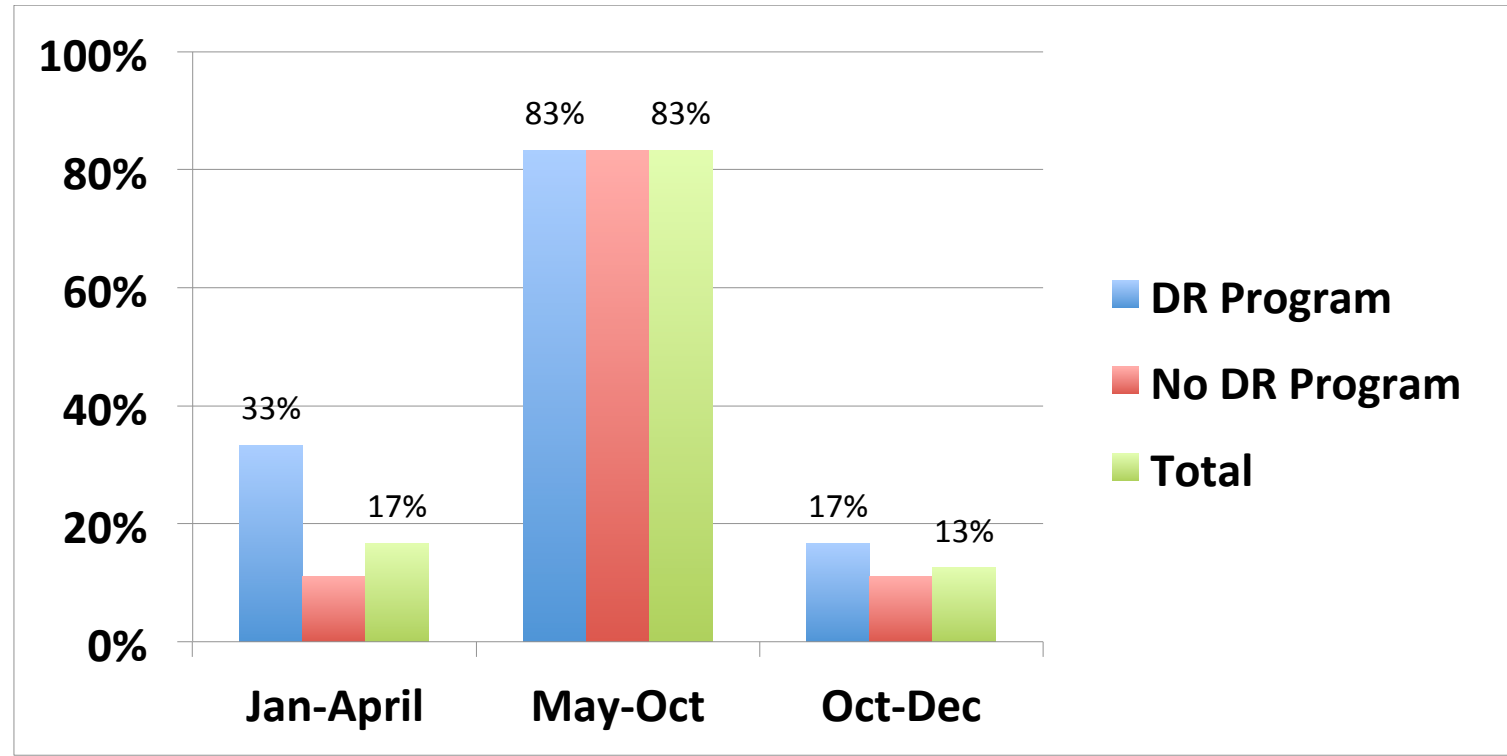


Figure C-10: Seasonal Variations in Electricity Demand by Industrial Sector

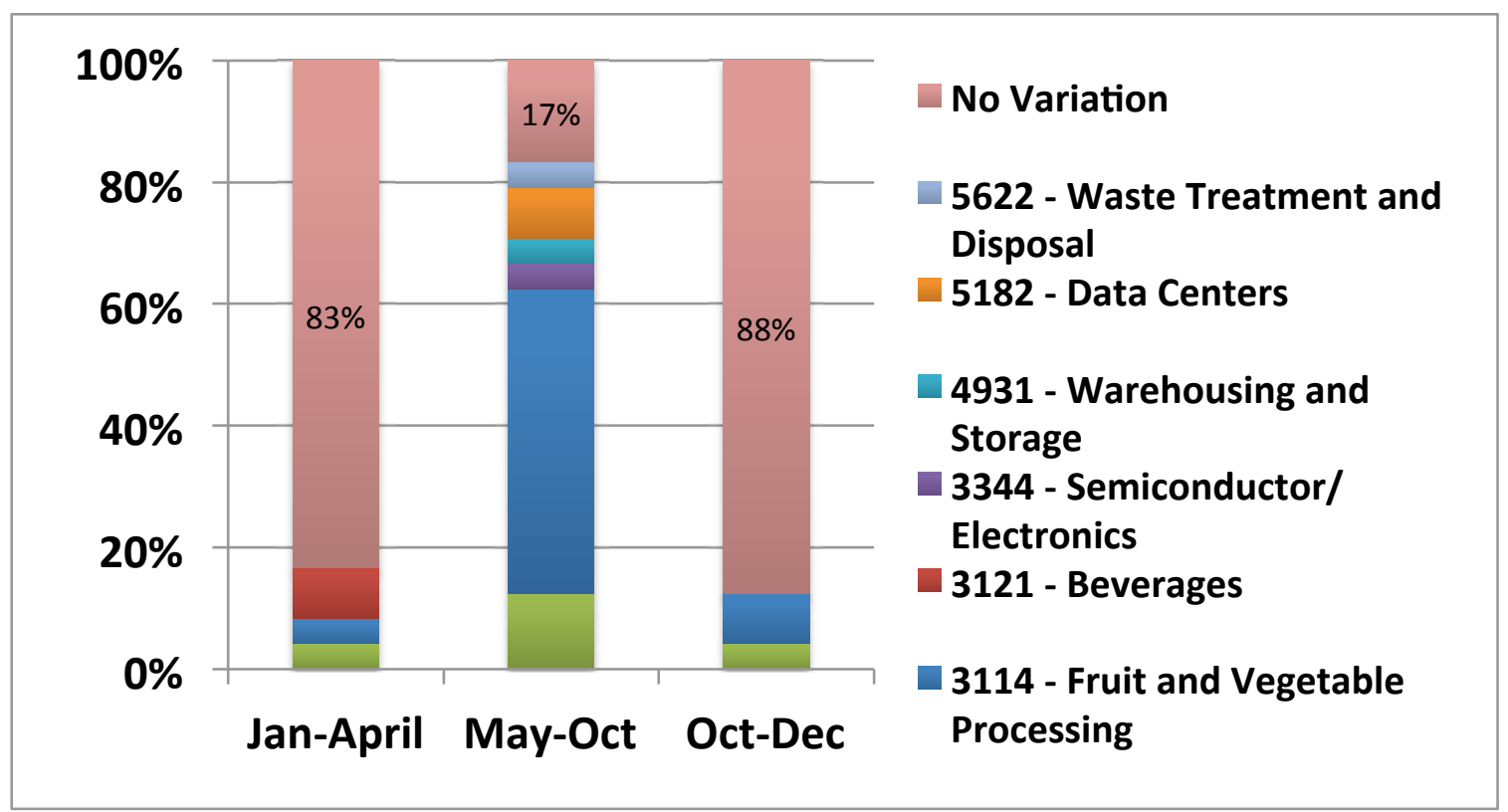

Figure C-11: Control Process Type (Fully/Semi-Automatic or Manual)

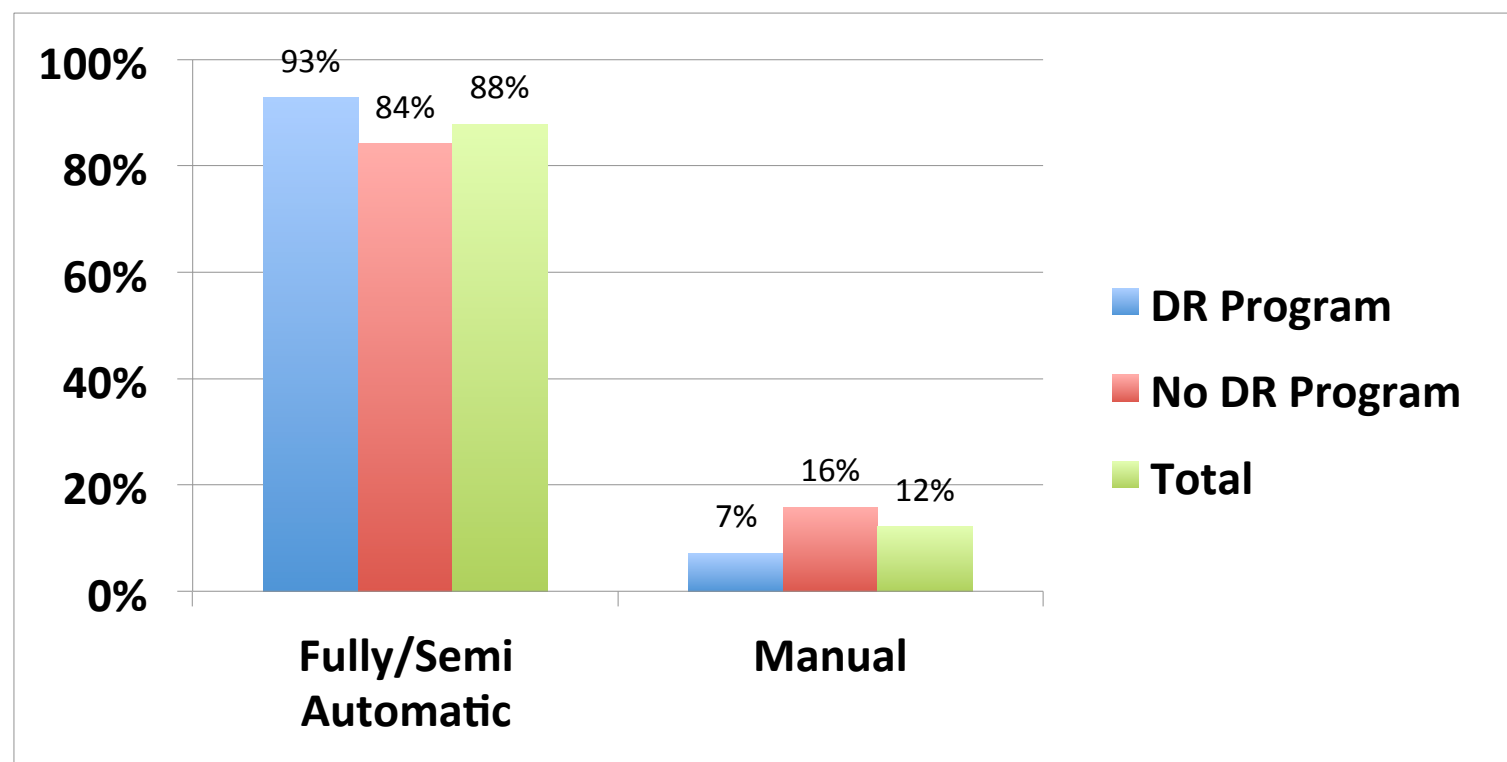


Figure C-12: Control System Vendor

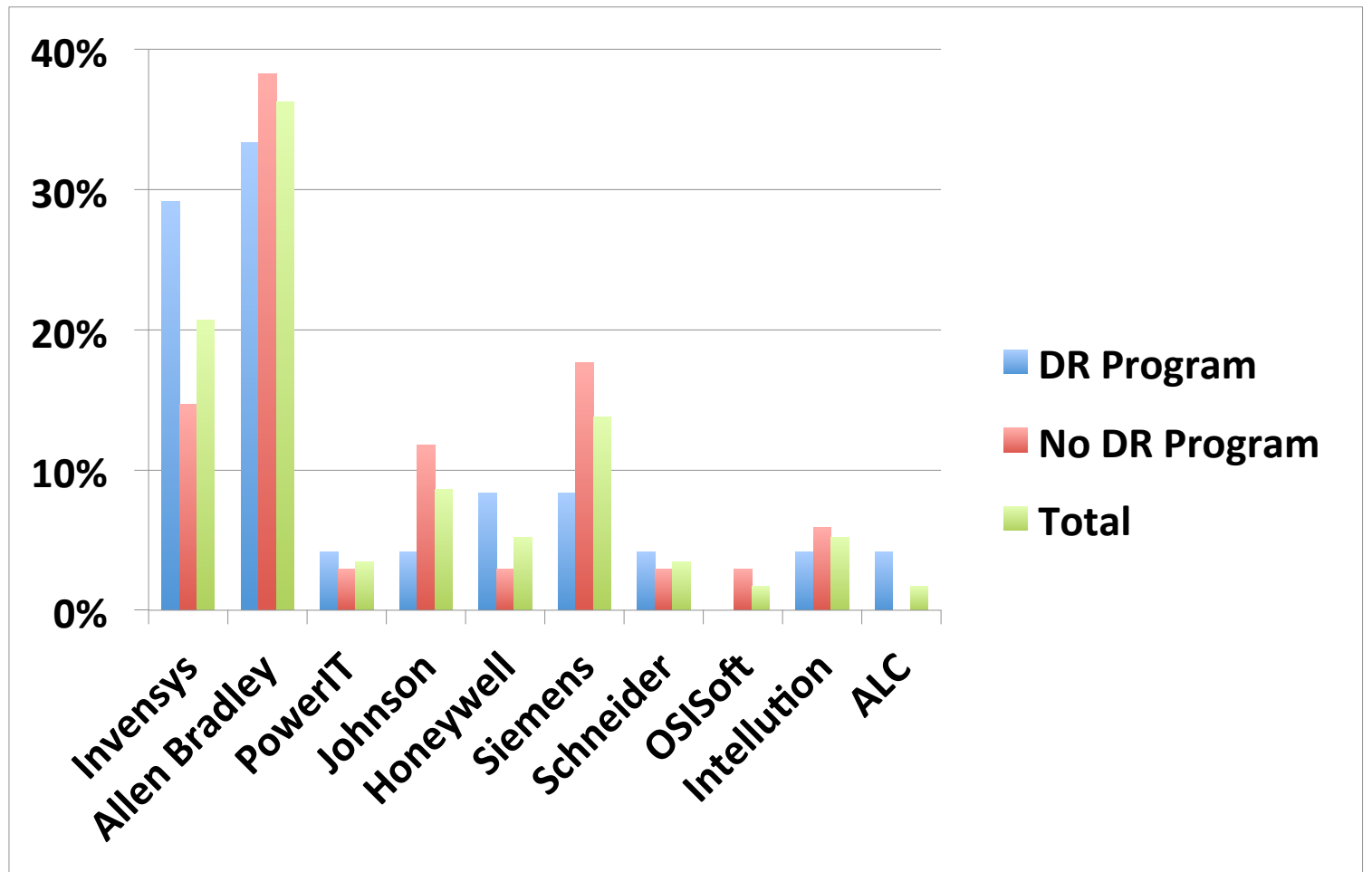

Figure C-13: Management of Control Networks

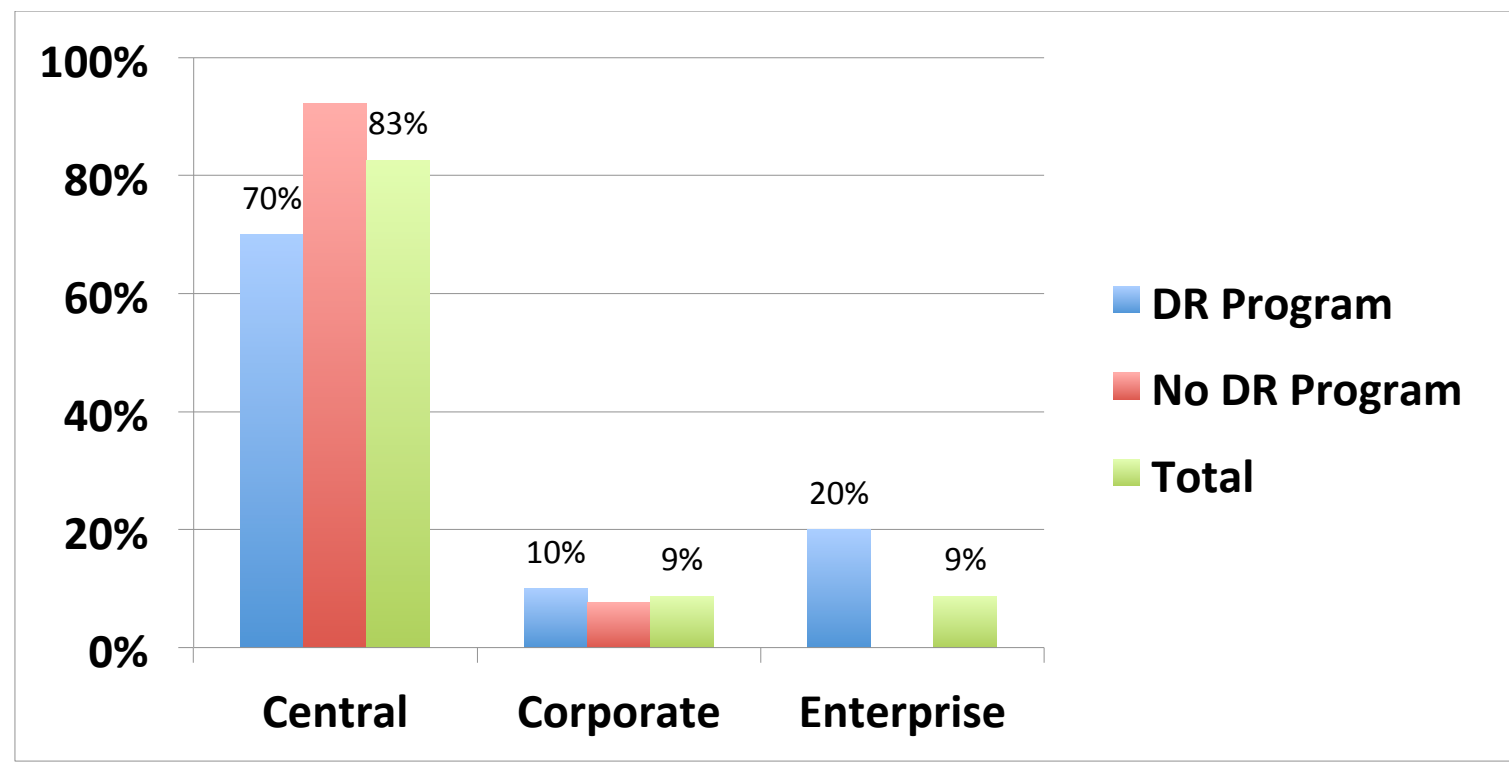


Figure C-14: Control System Use with End-Use Loads

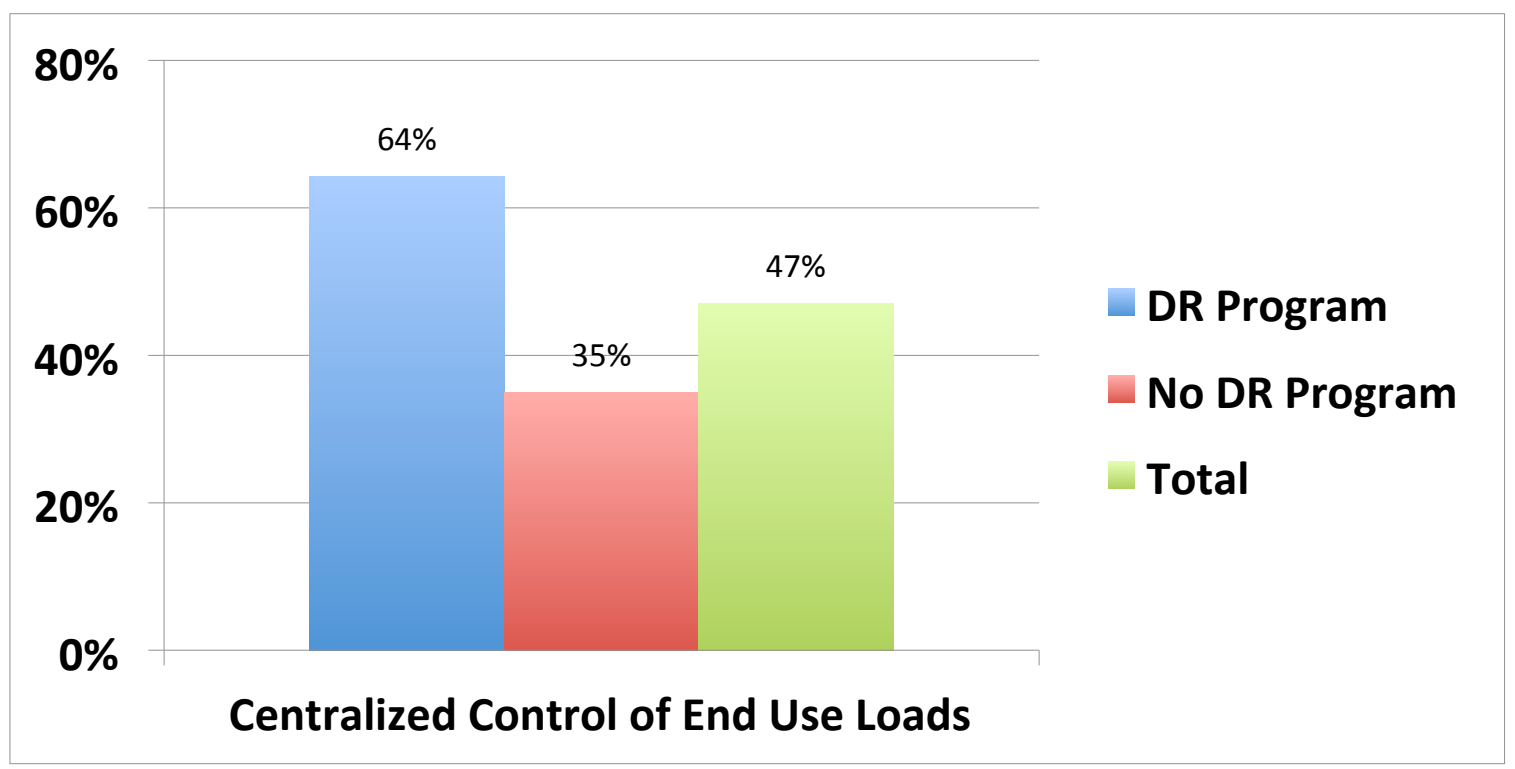

Figure C-15: Batch vs. Continuous Processes at Respondents Facilities

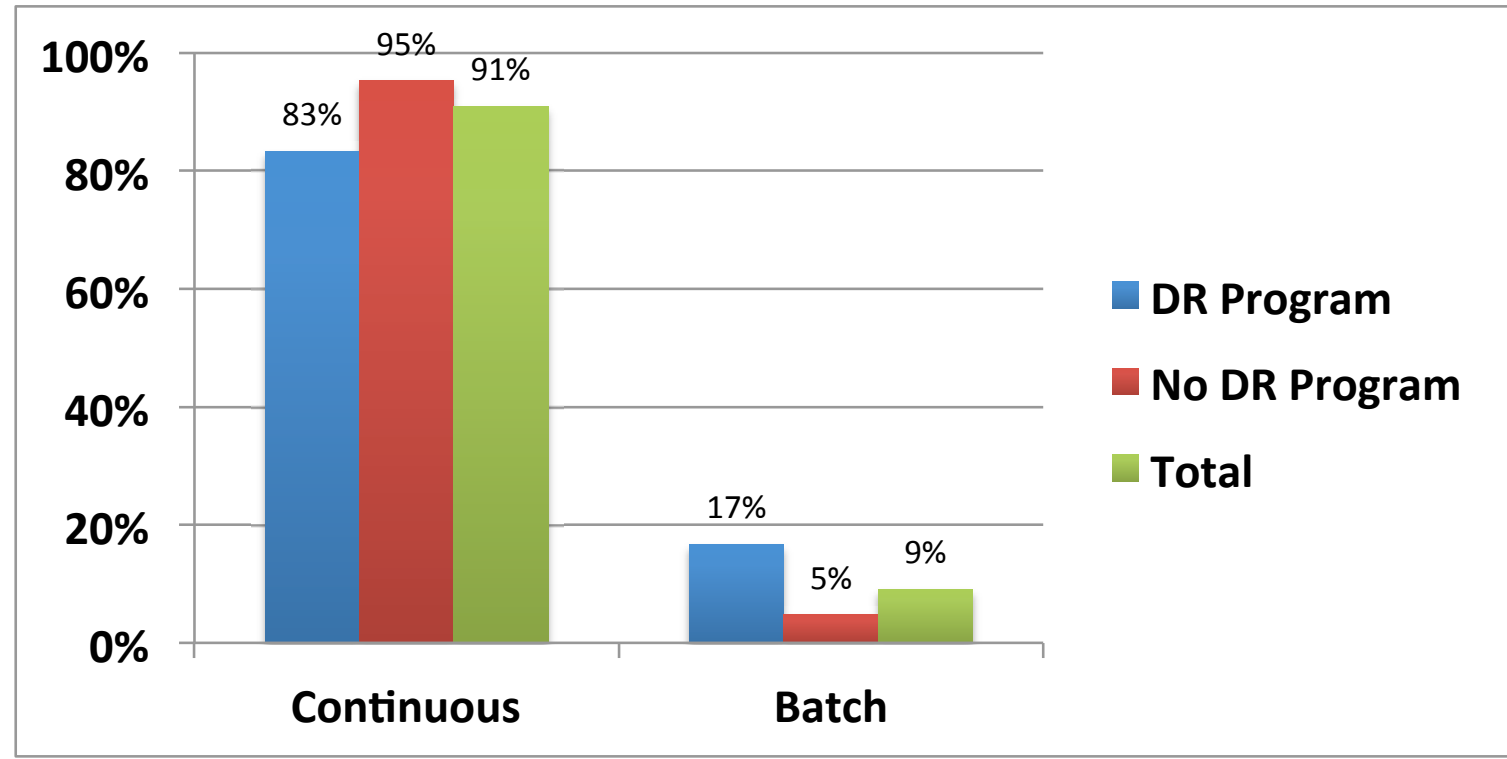


Figure C-16: Do Production Processes Consume More Than 25\% of Demanded Electricity?

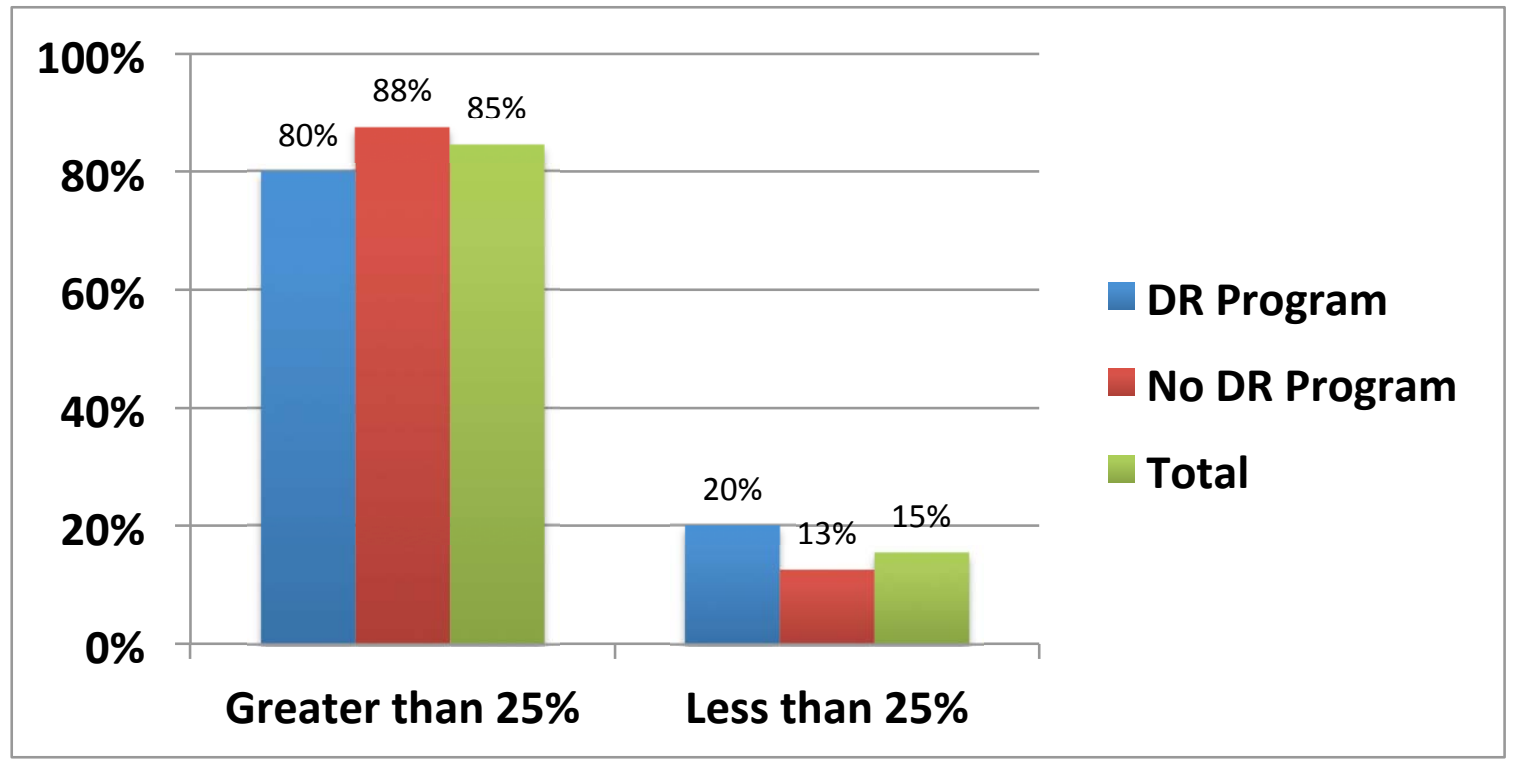

Figure C-17: Production Processes with Demand is Greater Than 25\%

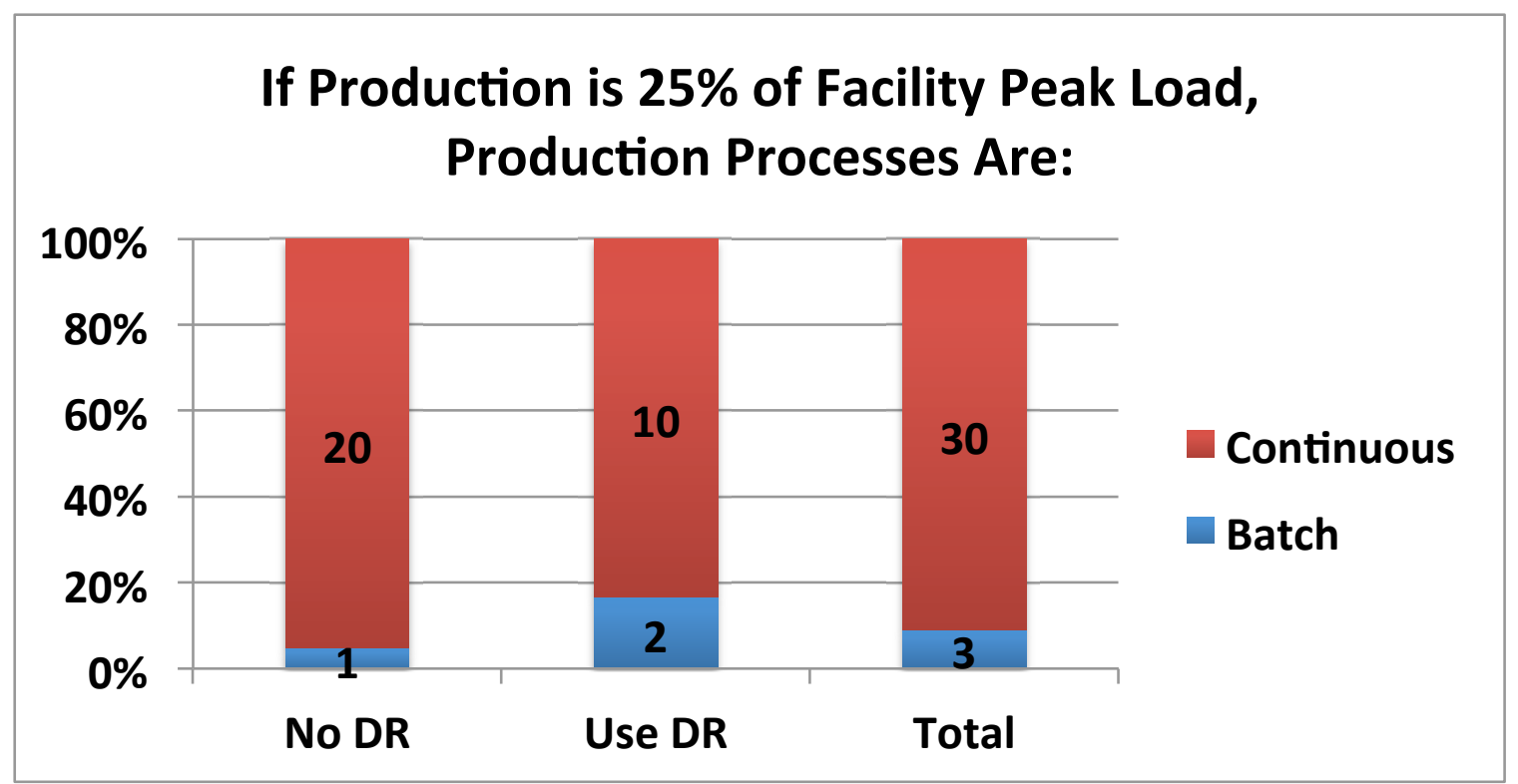


Figure C-18: Automatic Shutdown

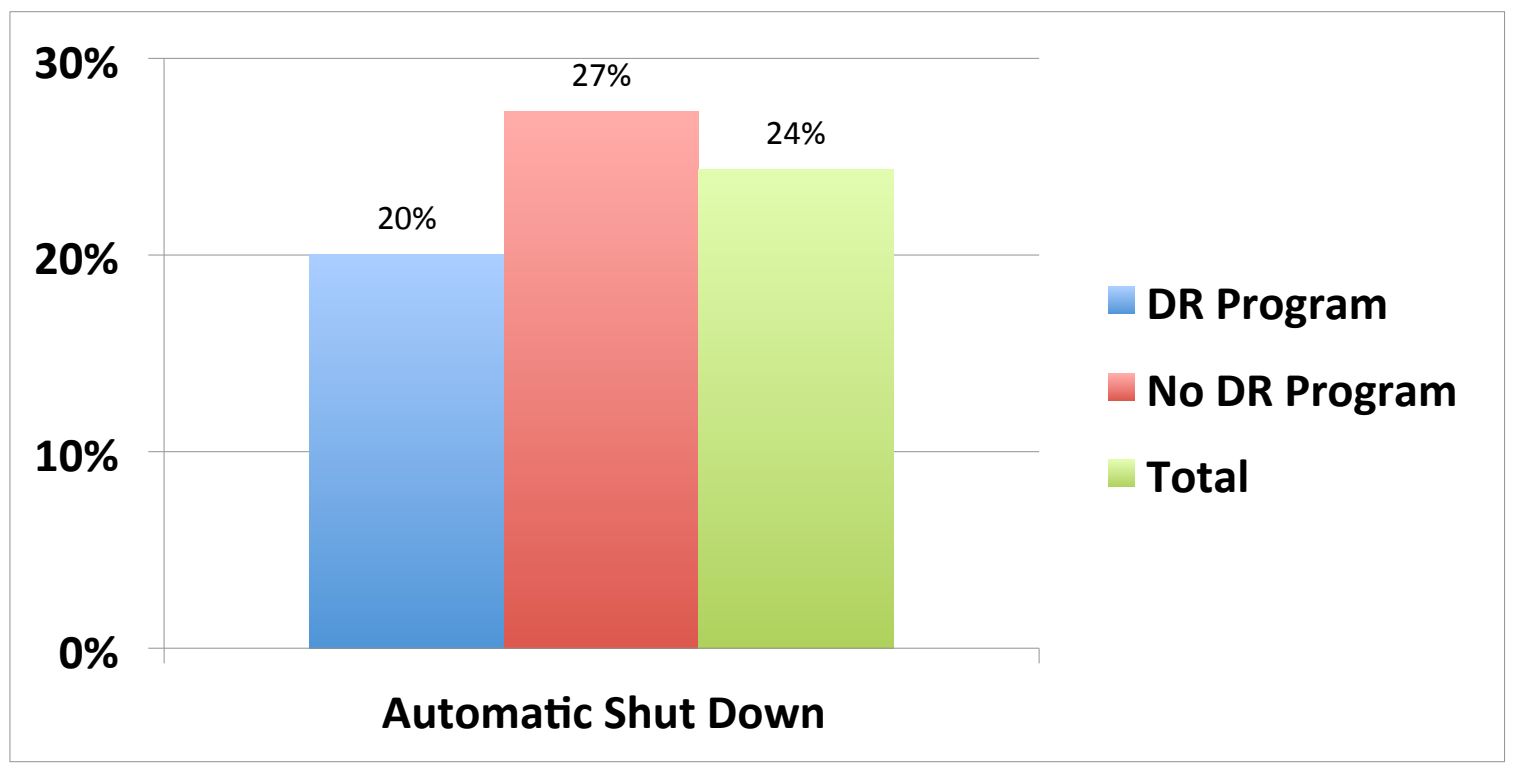

Figure C-19: Facility Energy Audits

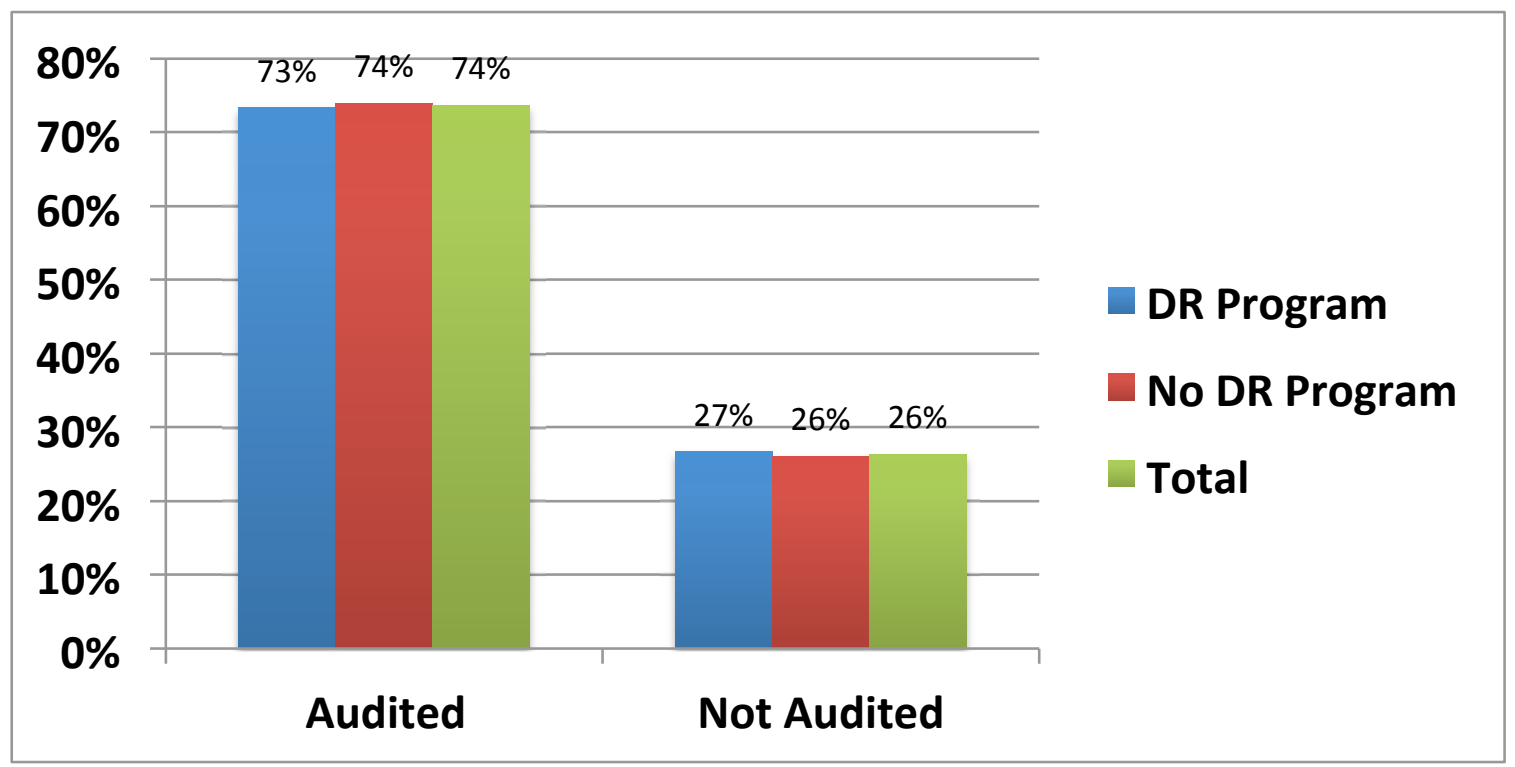


Figure C-20: Focus of Audit

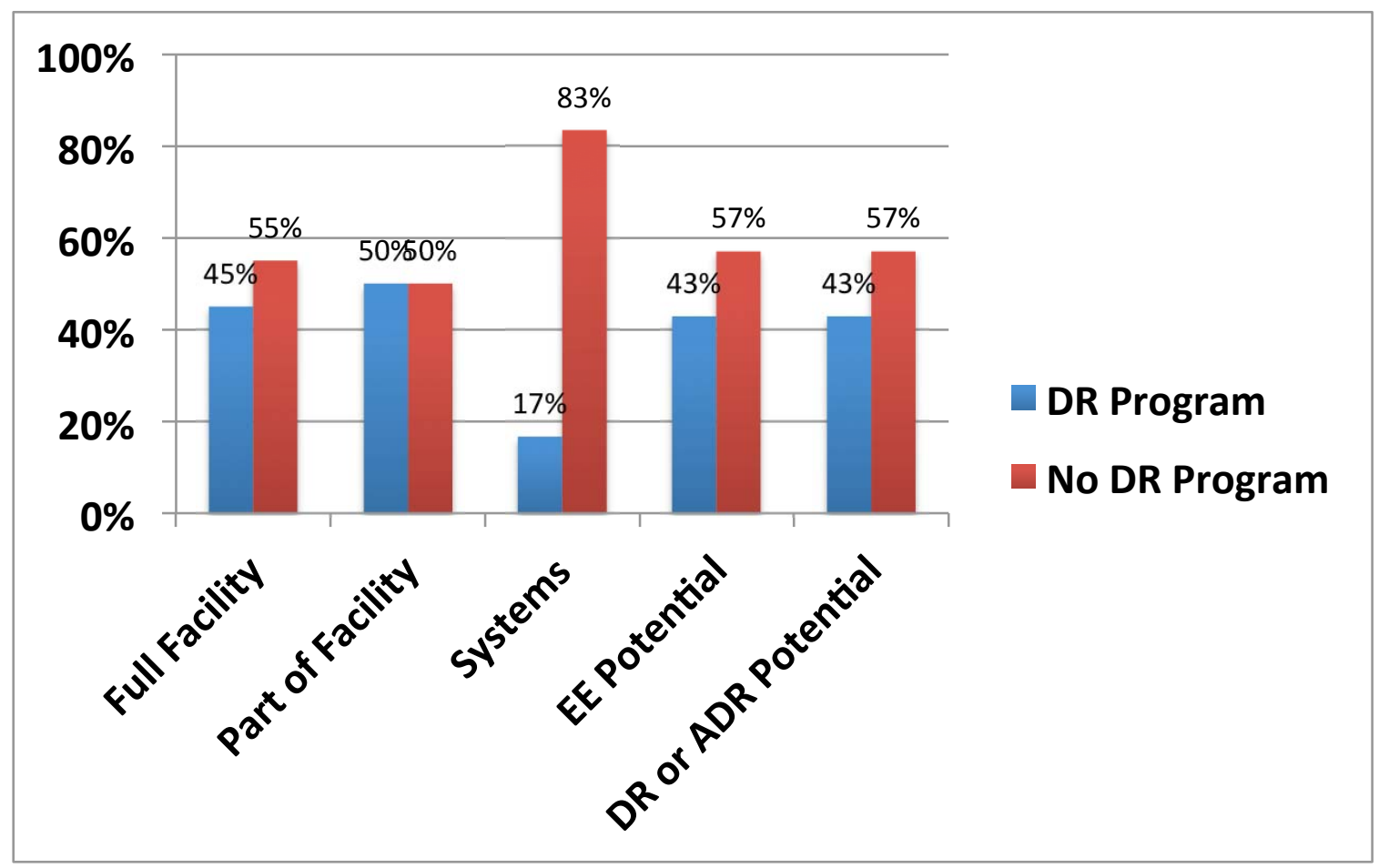

Figure C-21: DR Decision Maker

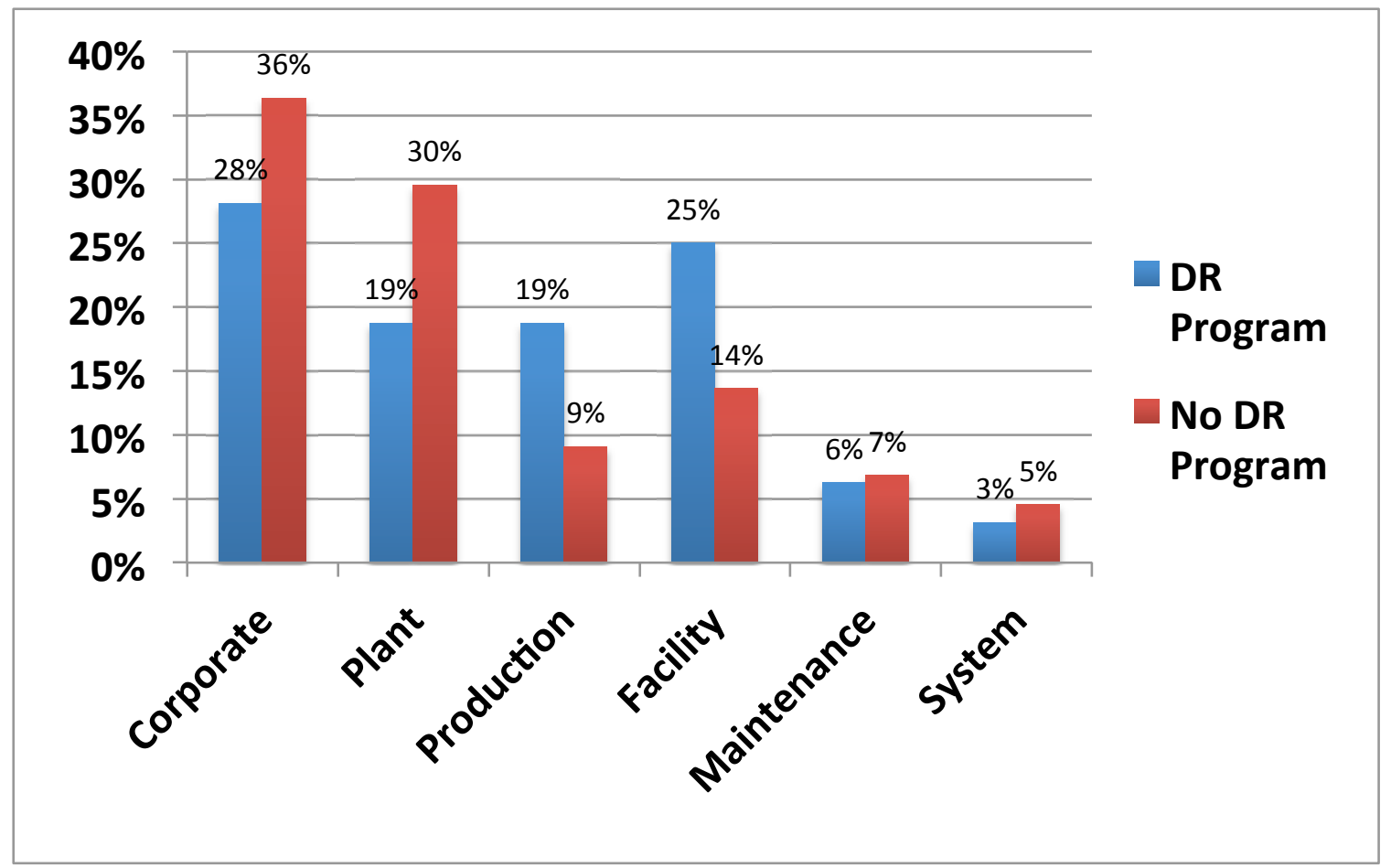


Figure C-22: Perceived Barrier to DR Participation

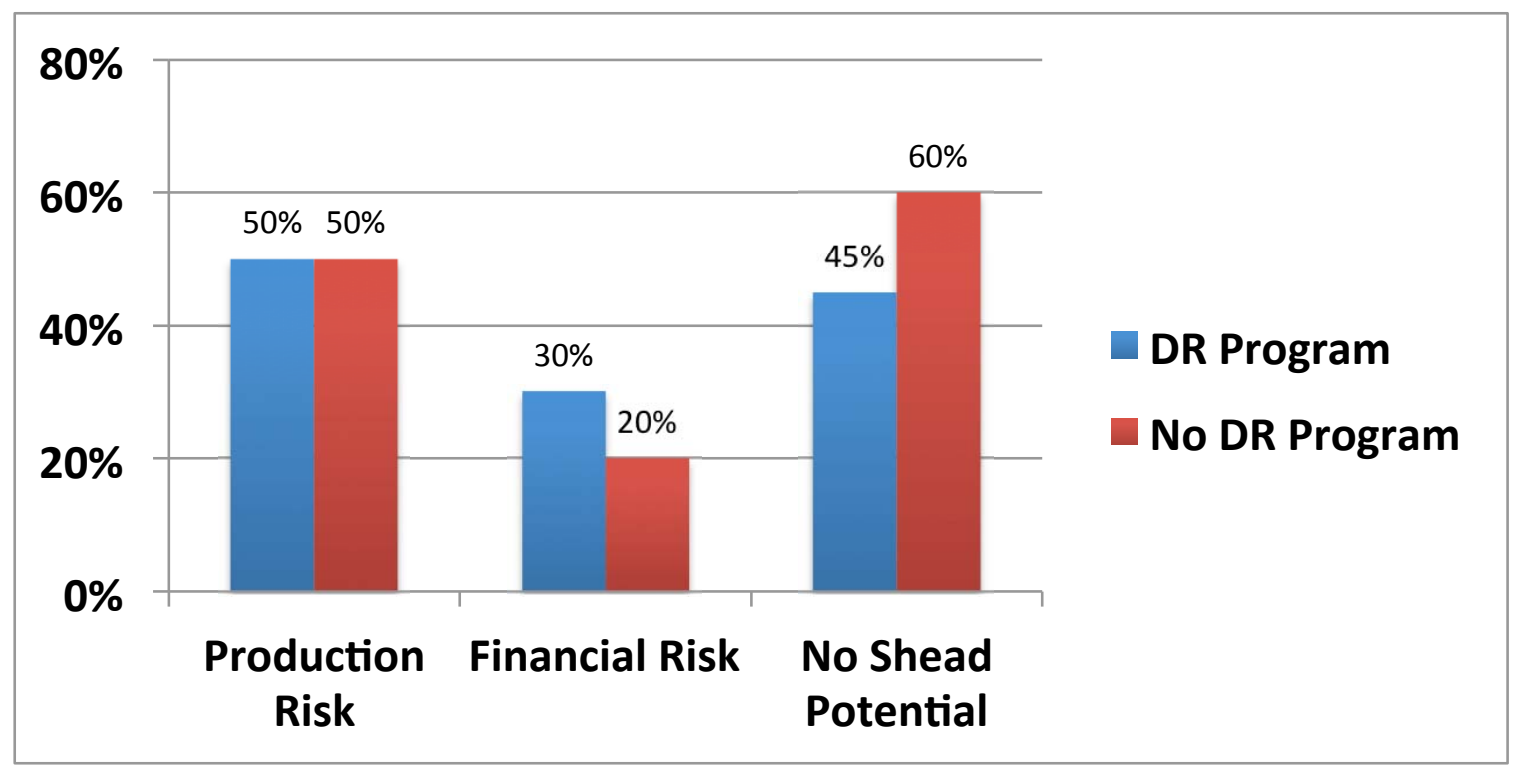

Figure C-23: Desired Features/Benefits of DR Participation

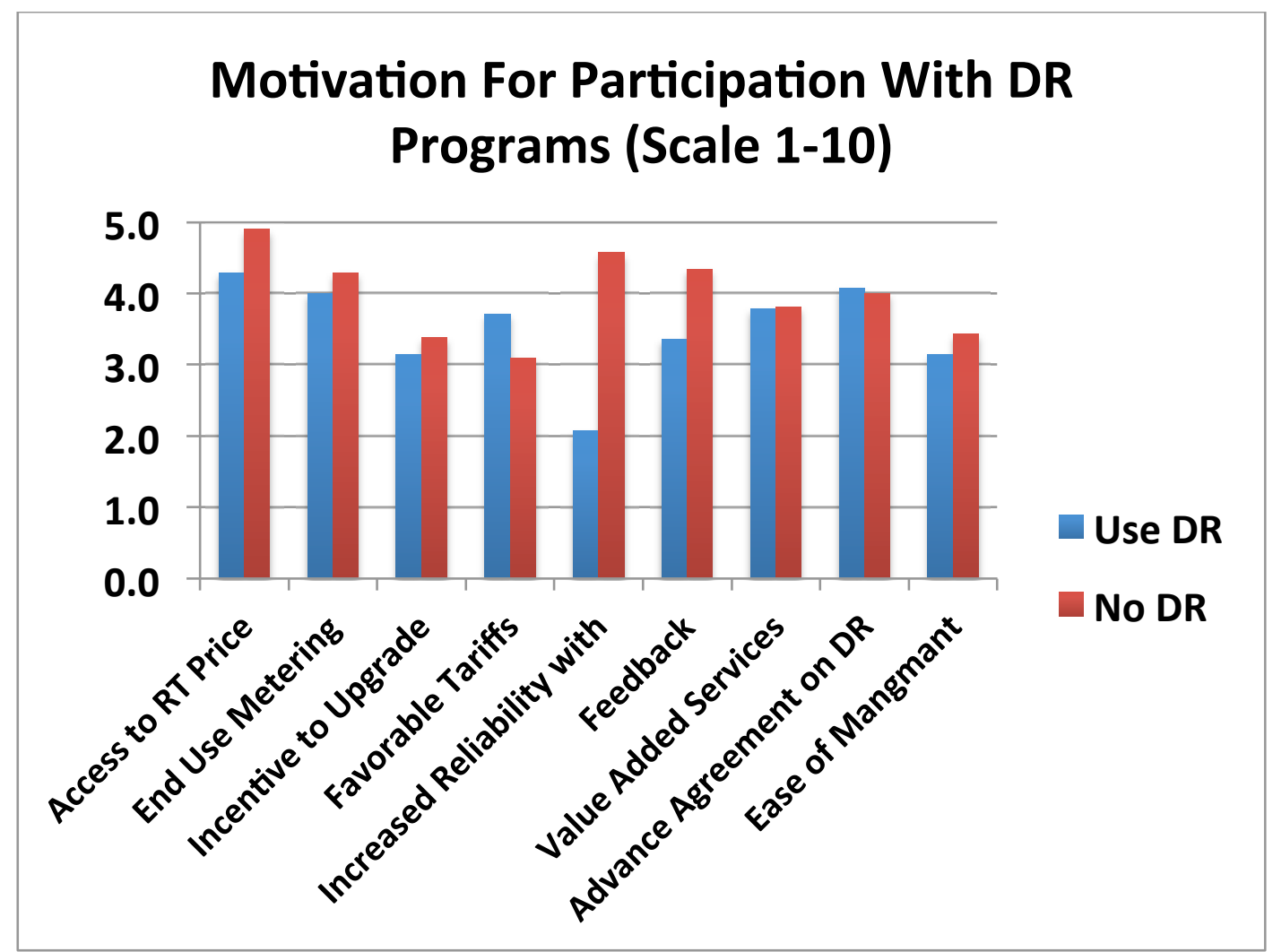




\section{Appendix D Survey Questionnaire Submitted to Respondents}




\section{Facility Information}

1. Contact and location information (to be kept confidential) - Text field

\begin{tabular}{|l|l|}
\hline Company: & \\
\hline Address: & \\
\hline Contact person(s): & \\
\hline E-mail(s): & \\
\hline Telephone(s): & \\
\hline
\end{tabular}

2. Is this facility an industrial plant?

$\square$ No (If checked then EXIT Survey)

Yes

If Y then, the business or industrial sector type is - Check one (link to NAICS code) -

$\square$ 2213, Water and wastewater treatment

3114, Fruit and Vegetable Processing

$\square$ 3118, Bakeries and Tortillas

3121, Beverages

3132, 3133, 3341, Fabric Mills \& Textiles

3222, Converted Paper Products

3231, Printing

3241, Petroleum/Coal

3251, Basic Chemicals (Includes Industrial Gas)

3254, Pharmaceuticals/Medicine

3261, Plastics

3262, Rubber Products

3273, Cement and Concrete

3323, Architectural and Structural Metals

3328, Coating, Engraving, Heat Treating, and Allied Activities

3329, Other Fabricated Metals

3332, Industrial Machinery

3341, Computer and Peripherals

3342, Communications Equipment

3344, Semiconductor/Electronics

3363, Motor Vehicle Parts

3364, Aerospace

3371, 3372, Household and Office Furniture/Fixtures

4931, Warehousing and Storage

5182, Data Centers

5622, Waste Treatment and Disposal

0000 , Other (Please specify (Text field) - 
3. What is the electricity use in your facility?

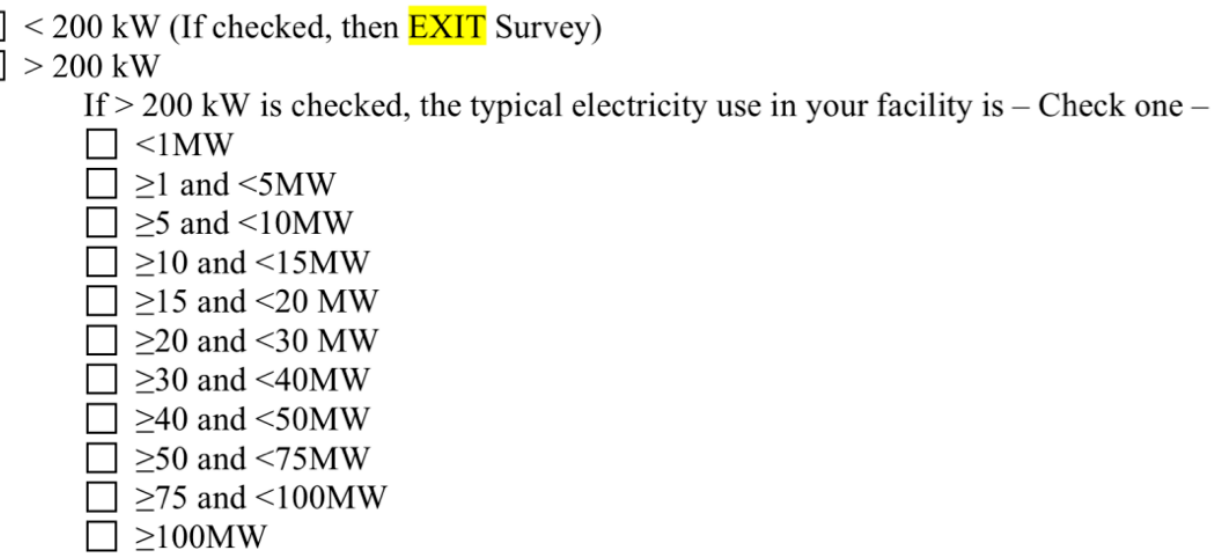

4. Does facility electrical use vary by season(s) as opposed to consistent year-around operation?

\section{No (Go to NEXT question)}

$\square$ Yes

If Y then, the typical peak season(s) are - Check all that applies -

$\square$ Jan-April

$\square$ May-October

$\square$ October-Dec

5. Does this site include more than one facility (e.g., recognized as a separate business)? - Check one

No (Go to NEXT question)

Yes

If Y then, how many facilities? (Text field or range)

6. What is the plant's annual purchased electricity bill from all sources? - Check one -

$\square<\$ 2$ million

$\square \geq \$ 2$ million and $<\$ 5$ million

$\square \geq \$ 5$ million and $<\$ 10$ million

$\square \geq \$ 10$ million and $<\$ 20$ million

$\geq \geq 20$ million

7. Does this facility self-generate electricity (e.g. Biomass, steam, renewables, etc.)?

$\square$ No (Go to NEXT question)

$\square$ Yes

If $Y$ then, the source of electricity generation is - Check all -

$\square$ Biomass

$\square$ Steam

$\square$ Renewable energy

$\square$ Diesel

$\square$ Waste

Other (Please specify - 
8. Which utilities provide the facility with electricity? - Check all applicable -

Pacific Gas and Electric Company (PG\&E)

Southern California Edison (SCE)

San Diego Gas and Electric (SDG\&E)

Direct Access customer of above utilities

Municipal Utility District

Irrigation District

Other (Please specify ) (Text field)

9. Do you do utility bill cost analysis (e.g., multiple pricing and usage scenarios for electricity)?

No

Yes

10. Does the facility have at least one utility electric meter (e.g., interval meter)?

No (go to NEXT question)

Yes

If $\mathrm{Y}$, does the facility have additional meters to measure specific areas, process, and equipments?

$\square$ Yes

$\square$ No

If $\mathrm{Y}$ then,

A. How many additional meters does the facility have?

$\square 1-2$

$2-5$

$\square-10$

$\square>10$

B. Are these meters on different electric rates?

$\square$ Yes

No

C. Are these meters measuring industrial and commercial electricity use separately?

$\square$ Yes

$\square$ No

\section{Process Systems, Support, Connected, and Peak Loads}

11. Do you know your facility's total connected load?

No (go to NEXT question)

Yes,

If $\mathrm{Y}$, then the total facility's connected load (as opposed to demand load) is - Check one -

$\square>1$ and $<5 \mathrm{MW}$

$\geq 5$ and $<10 \mathrm{MW}$

$\geq 10$ and $<15 \mathrm{MW}$

$\geq 15$ and $<20 \mathrm{MW}$

$\geq 20$ and $<25 \mathrm{MW}$

$\geq 25$ and $<30 \mathrm{MW}$

$\geq 30$ and $<40 \mathrm{MW}$

DRRC Industrial Controls Systems and IT Systems Survey - Final - v10.1 
12. Do you know which facility and end-use processes are responsible for peak loads?

$\square$ No (Go to NEXT question)

$\square$ Yes

If $\mathrm{Y}$ then,
A. The total load at peak usage is - Check one -
$\square>1$ and $<5 \mathrm{MW}$
$\square \geq 5$ and $<10 \mathrm{MW}$
$\square \geq 10$ and $<15 \mathrm{MW}$
$\square \geq 15$ and $<20 \mathrm{MW}$
$\geq 20$ and $<25 \mathrm{MW}$
$\geq 25$ and $<30 \mathrm{MW}$
$\geq 30$ and $<40 \mathrm{MW}$
$\geq 40$ and $<50 \mathrm{MW}$
$\geq 50 \mathrm{MW}$

B. What end uses are responsible for peak loads and for what fraction of the peak load? (Check all applicable)

\begin{tabular}{|l|l|l|l|l|l|l|}
\hline \% Peak Load & $<5 \%$ & $\mathbf{5 - 1 0 \%}$ & $\mathbf{1 0 - 2 0} \%$ & $\mathbf{2 0 - 3 0 \%}$ & $\mathbf{3 0 - 5 0 \%}$ & $\mathbf{7 5 0}$ \\
\hline $\begin{array}{l}\text { Specific process } \\
\text { equipment }\end{array}$ & & & & & \\
\hline $\begin{array}{l}\text { Production support (air } \\
\text { compressors, chilled } \\
\text { water, water treatment, } \\
\text { forklift charging, scrubbers) }\end{array}$ & & & & & & \\
\hline $\begin{array}{l}\text { Shift change or other } \\
\text { operational uses }\end{array}$ & & & & & & \\
\hline $\begin{array}{l}\text { Building equipment } \\
\text { (HVAC, lighting, etc.) }\end{array}$ & & & & & & \\
\hline Flat loads & & & & & & \\
\hline $\begin{array}{l}\text { Other equipment } \\
\text { (Please specify) }\end{array}$ & & & & & & \\
& & & & & & \\
\hline
\end{tabular}

13. Are facility operations subject to wide swings (5-10\%) in electrical usage on a daily basis?

$\square$ No (Go to NEXT question)

$\square$ Yes

If $\mathrm{Y}$ then, the typical peak hours are - Check all that applies -

$\square$ 8PM-12PM

$\square$ 12PM-2PM

$\square$ 2PM-4PM

$\square$ 4PM-6PM

6PM-8PM 
14. Are the production processes more than $25 \%$ of your facility's peak load?

$\square$ No (Go to NEXT question)

Yes

If $\mathrm{Y}$, then, these productions processes are - check one

$\square$ Batch

Continuous processes

15. Can any process equipment with a load of $50 \mathrm{~kW}$ or more be automatically shutdown without operator intervention?

$\square$ No (Go to NEXT question)

Yes

If $\mathrm{Y}$ then, what peak load is (or can be) serviced by automated controls is (check all applicable) -

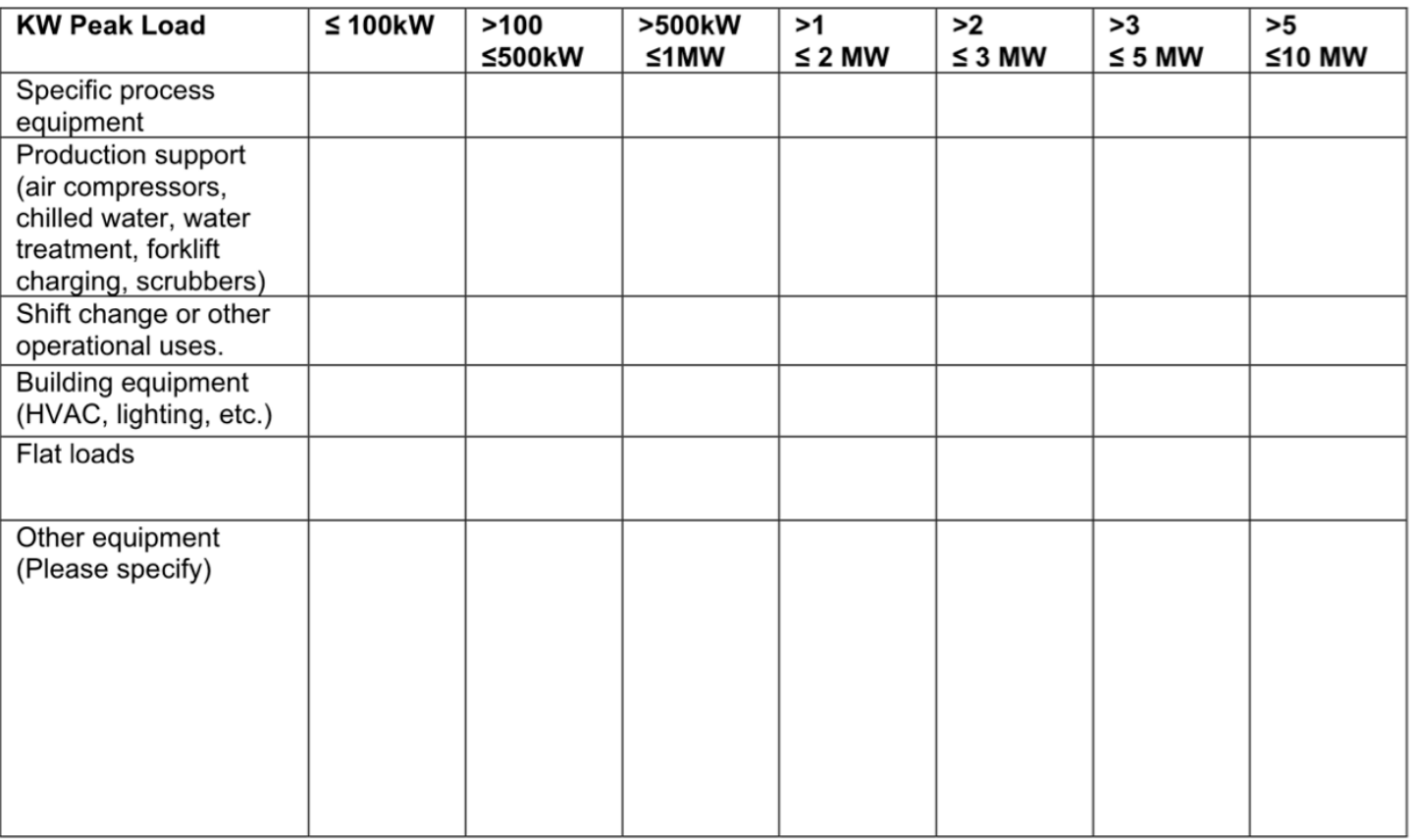

\section{Facility DR Potential}

16. Has your facility conducted an audit to estimate Energy Efficiency or Demand Response potential?

\section{No (Go to NEXT question)}

Yes

If $Y$ then,

A. How long ago was the audit conducted? Check One -

$\square<1$ year

$\square$ 1-2 years

2-4 years

$>4$ years

DRRC Industrial Controls Systems and IT Systems Survey - Final - v10.1 
B. What was audited? - Check all applicable -

$\square$ Entire facility

$\square$ Partial facility

$\square$ A single systems or process

$\square$ Energy Efficiency potential

$\square$ Demand Response (DR) and/or Automated DR (Auto-DR) potential.

Integrated DR (or Auto-DR) and Energy Efficiency potential

C. Was this audit conducted through a utility or similar entity?

No (Go to NEXT question)

Yes

If $\mathrm{Y}$ then,

C1. The utility name is - Check all applicable.

$\square$ Pacific Gas and Electric Company (PG\&E)

$\square$ Southern California Edison (SCE)

$\square$ San Diego Gas and Electric (SDG\&E)

$\square$ Direct Access customer of above utilities

$\square$ Municipal Utility District

$\square$ Irrigation District

Other (Please specify (Text field)

C2. Did the audit specify any detailed Demand Response (DR) opportunities?

$\square$ Yes

$\square$ No

17. Should the facility participate in Auto-DR, the decision maker would be: (check all applicable) -

\begin{tabular}{|l|l|l|l|l|l|l|l|}
\hline $\begin{array}{l}\text { Facility Auto-DR } \\
\text { Decision Maker }\end{array}$ & $\begin{array}{l}\text { Corporate } \\
\text { Management }\end{array}$ & $\begin{array}{l}\text { Plant } \\
\text { Manager }\end{array}$ & $\begin{array}{l}\text { Production } \\
\text { Manager }\end{array}$ & $\begin{array}{l}\text { Facilities } \\
\text { Manager }\end{array}$ & $\begin{array}{l}\text { Maintenance } \\
\text { Supervisor }\end{array}$ & $\begin{array}{l}\text { Systems } \\
\text { Operator }\end{array}$ & $\begin{array}{l}\text { Other } \\
\text { (Name) }\end{array}$ \\
\hline $\begin{array}{l}\text { To determine } \\
\text { whether or not to } \\
\text { participate in } \\
\text { Auto-DR }\end{array}$ & & & & & & & \\
\hline $\begin{array}{l}\text { If the estimated } \\
\text { shed/shift would } \\
\text { have any impact } \\
\text { on operation or } \\
\text { production }\end{array}$ & & & & & & & \\
\hline
\end{tabular}

18. Is the facility participating or has participated in any Demand Response Programs?

No (Go to NEXT question)

Yes

If $\mathrm{Y}$ then,

A. What DR program(s) this facility is enrolled? - Check all -

$\square$ Critical Peak Pricing Program (CPP)

$\square$ Demand Bidding Program (DBP)

$\square$ Capacity Bidding Program (CBP)

$\square$ Business Energy Coalition Program (BEC)

Other (Please specify -

) (Text field) 
B. What's the facility peak demonstrated DR load reduction? - Check one -
$\geq 100 \mathrm{~kW}$ and $<500 \mathrm{~kW}$
$\geq 500 \mathrm{~kW}$ and $<1 \mathrm{MW}$
$\geq 1 \mathrm{MW}$ and $<2 \mathrm{MW}$
$\geq 2 \mathrm{MW}$ and $<3 \mathrm{MW}$
$\geq 3 \mathrm{MW}$ and $<5 \mathrm{MW}$
$\geq 5$ and $<10 \mathrm{MW}$
$\geq 10$ and $<20 \mathrm{MW}$

C. The facility end-uses that contributed to DR are (check all applicable)

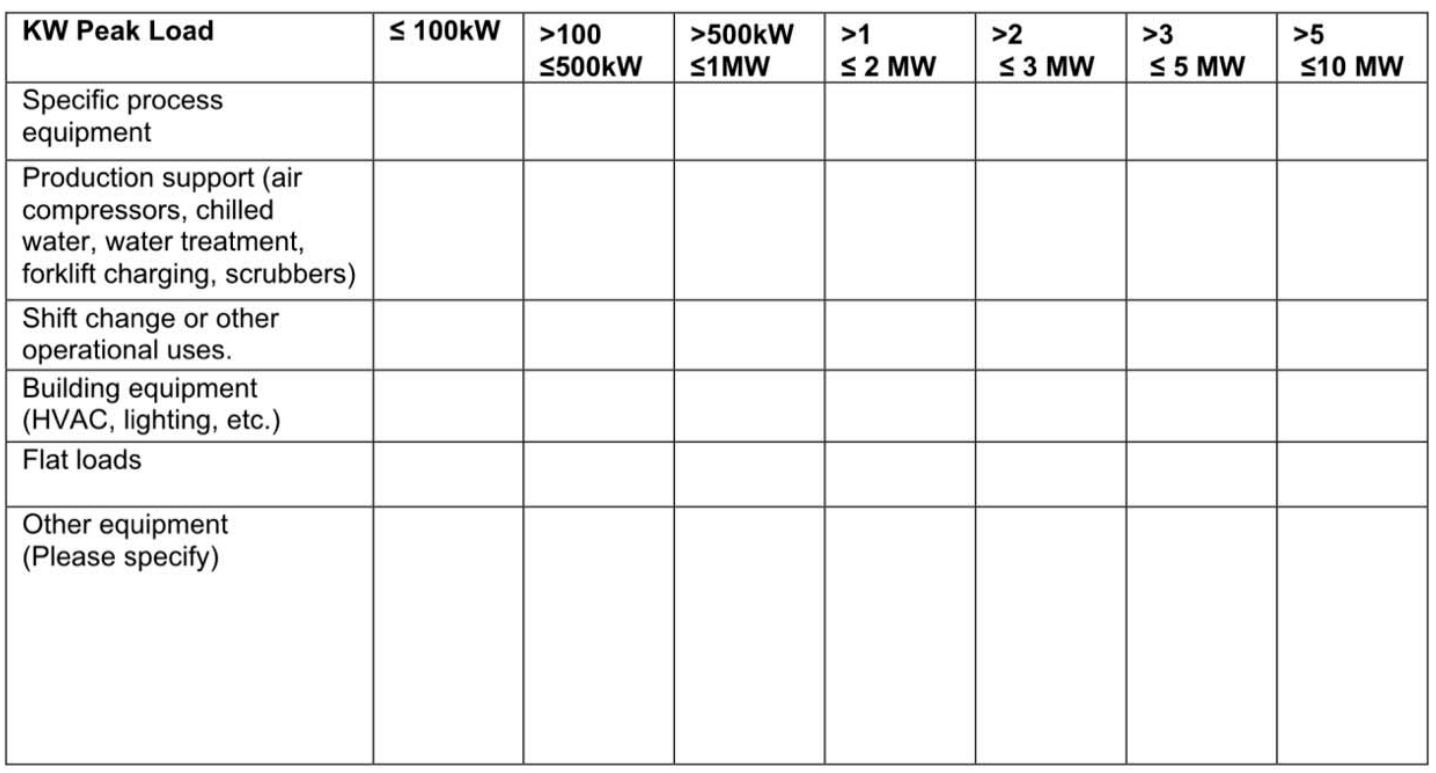

D. What were facility minimum hours of participation? - Check one -

$\square 2$ hours

2-4 hours

4-6 hours

$\square$ 6-8 hours

Other (Please specify -

) (Text field)

E. How did the facility participate in DR program? - Check one -

$\square$ Directly with the utility

Through a third-party (aggregator)

19. What are the major barriers to participate in any DR program? - Check all -

Perceived production risk

Inadequate financial benefit

Cannot shed/shift production

Restructuring/retooling

Others (Please specify -

) (Text field) 


\section{Controls and IT Systems, and Security}

20. Does the facility have Energy Management Control Systems (EMCS) or other industrial control systems (PLC, DCS, SCADA, etc. ${ }^{1}$ )?

No

If $\mathrm{N}$ then, do you have any plans for installation or upgrade in near-term?

$\square$ No (Jump to "Miscellaneous" section - Question 28)

Yes

Yes (Go to question 20.C and Jump to "Miscellaneous" section - Question 28)

If $\mathrm{Y}$ then,

A. The control system is used for following facility end uses - Check all applicable

$\square$ Processes

$\square$ Operations

$\square$ Packaging

$\square$ Warehouse

HVAC

Lighting

Other (Please specify -

) (Text field)

B. Facility Process control is primarily - Check One

$\square$ Manual

Semi-Automated

Fully-Automated

C. The controls vendor or manufacturer name is - Check all that apply

$\square$ Invensys Wonderware ${ }^{\circledR}\left(\right.$ E.g. InTouch ${ }^{\mathrm{TM}}$ )

Allan Bradley or Rockwell Automation (E.g. RSView ${ }^{\circledR 32} 2^{\mathrm{TM}}$ )

$\square$ PowerIT Solutions (E.g. Spara ${ }^{\mathrm{TM}}$ )

$\square$ Johnson Controls Inc. (E.g. Metasys $\left.{ }^{\circledR}\right)$

Honeywell (E.g. Enterprise Buildings Integrator ${ }^{\mathrm{TM}}$ )

Siemens (E.g. SIMATIC® PCS 7)

$\square$ Schneider Electric or Andover Controls or TAC

OSISoft (E.g. PI System)

Intellution (E.g. FIX DMACS)

Automated Logic Corporation (ALC)

Others (Please specify -

) (Text field)

21. Does the facility use control systems for any peak load management or demand limiting ${ }^{2}$ strategies? $^{2}$

Yes (Go to NEXT question)

No

If $\mathrm{N}$ then, any installation planned for such a strategy (peak load management or demand limiting ${ }^{3}$ ) strategies?

$\square$ Yes

No

${ }^{1}$ Refer "Attachment" for definition of control systems.

${ }^{2}$ Refer "Attachment" for definitions.

${ }^{3}$ Refer "Attachment" for definitions.

DRRC Industrial Controls Systems and IT Systems Survey - Final - v10.1 
22. Do these facility control systems have the ability to track trend-log data?

No (Go to NEXT question)

Yes

If $\mathrm{Y}$ then, the duration of trend-log is - Check one

$\square<1$ week

$\square 1-2$ weeks

$>2$ weeks

23. Does your facility use control systems to collect any electricity demand data?

No (Go to NEXT question)

Yes

If $\mathrm{Y}$ then, the type of data collected is - Check all -

$\square$ Peak load

$\square \mathrm{KW}$

$\square$ Operating times

$\square$ End-use loads

$\square$ Other (Please specify -

) (Text field)

24. Is control system managed at individual end-use loads?

Yes (Go to NEXT question)

No

If $\mathrm{N}$ then,

A. The control system is managed by a - Check one

$\square$ Centralized Network

$\square$ Corporate Network

Enterprise Network

B. Are control systems automation networked using Internet?

$\square$ No

If $\mathrm{N}$ then, any near term plan to upgrade controls for Internet connectivity?

$\square$ Yes

Yes

If $\mathrm{Y}$ then,

B1. The Internet connection type is - Check one-

$\square$ T1 Line or greater

$\square$ DSL

Broadband

Cable

Dial-up

Other (Please specify -

) (Text field)

B2. Control systems can host or can be customized to host Web Service (such as XML)?

$\square$ Yes

$\square$ No

B3. Control systems are serviced by Virtual Private or proprietary network (VPN)?

DRRC Industrial Controls Systems and IT Systems Survey - Final - v10.1 
Yes

No

B4. How is the network connection within the facility managed? - Check one -

$\square$ Wired

Wireless

Both

B5. Are control systems managed by a Local Area Network (LAN)?

$\square$ No (Go to NEXT question)

Yes

If Y then, the Local Area Network (LAN) is configured by - Check all

$\square$ A firewall

$\square$ Own proxy

$\square$ Own DNS server

$\square$ DHCP enabled IP

Static IP

25. The facility's control systems are programmed and serviced by - Check one

$\square$ Internal resources

$\square$ Third-party

Internal resources and/or third-party

26. Does facility have information technology (IT) or network or security policy?

Yes

$\square$ No

27. Does the facility control system have?

A. Centralized control of the end-use loads?

$\square$ Yes

$\square$ No

If $\mathrm{N}$ then, are there any plans to centralize facility control systems?

$\square$ Yes

$\square$ No

B. Is a Human Machine Interface (HMI) used to monitor end-use loads?

$\square$ No

Yes

If $Y$ then,

A1. Does HMI manage individual zone controls and other facility equipments?

$\square$ Yes

No

A2. Does HMI manage process equipments?

$\square$ Yes

No

DRRC Industrial Controls Systems and IT Systems Survey - Final - v10.1 
C. Facility use any Enterprise Resource Planning (ERP) or Supply-Chain Management (SCM) or Business Process Management (BPM) or Manufacturing Execution systems (MES)?

$\square$ Yes (Go to NEXT question)

No

If $\mathrm{N}$ then, are there any plans to install or upgrade to ERP or SCM or BPM or MES?

$\square$ Yes

No

\section{Miscellaneous}

28. What features of Automated Demand Response ${ }^{4}$ participation would provide the highest value for you? - Rank in priority from the highest (1) to the lowest (10) (Rating and text field)

Access to real-time pricing information

Increase in end-use metering

Incentives to upgrade facility controls

Favorable electricity tariffs and credits for participation

Increased reliability of service through automation

Feedback on DR participation

Value added services (DR opt-out capability, $24 \mathrm{hr}$ in advance notification, etc)

Advance agreement on DR black-out dates

Ease of management and participation

Other (Please specify -

END OF THE SURVEY - THANK YOU!

${ }^{4}$ Refer "Attachment" for definition

DRRC Industrial Controls Systems and IT Systems Survey - Final - v10.1 


\section{Appendix E}

\section{Control Expert Feedback Form}

\begin{tabular}{|c|c|c|}
\hline \multicolumn{3}{|c|}{ Subsector } \\
\hline \multicolumn{3}{|c|}{ Demand Response Ability Questions } \\
\hline Attribute & Rating (Selections) & Comments \\
\hline Overall DR Ability & $\begin{array}{l}\text { (1 - Very Low } \\
2 \text { - Low } \\
3 \text { - Medium } \\
4 \text { - High } \\
5 \text { - Very High) }\end{array}$ & \\
\hline $\begin{array}{l}\text { Technical DR Ability } \\
\text { (Level of controls / } \\
\text { automation) }\end{array}$ & $\begin{array}{l}\text { (1 - Very Low } \\
2 \text { - Low } \\
3 \text { - Medium } \\
4 \text { - High } \\
5 \text { - Very High) }\end{array}$ & \\
\hline Operational DR Ability & $\begin{array}{l}\text { (1 - Very Low } \\
2 \text { - Low } \\
3 \text { - Medium } \\
4 \text { - High } \\
5 \text { - Very High) }\end{array}$ & \\
\hline \multicolumn{3}{|c|}{ Energy Consumption Questions } \\
\hline Attribute & Electricity Use & Comments \\
\hline $\begin{array}{l}\text { Total Sector Electricity } \\
\text { Consumption in } \\
\text { California (MW) }\end{array}$ & & \\
\hline
\end{tabular}




\begin{tabular}{|c|c|c|}
\hline $\begin{array}{l}\text { Average Facility } \\
\text { Electricity Consumption } \\
(\mathrm{MW})\end{array}$ & & \\
\hline $\begin{array}{l}\text { Electricity Cost as a \% of } \\
\text { Operating Cost }\end{array}$ & & \\
\hline \multicolumn{3}{|c|}{ Process Questions } \\
\hline Attribute & Rating & Comments \\
\hline $\begin{array}{l}\text { Hour-to-hour Power } \\
\text { Demand Predictability }\end{array}$ & $\begin{array}{l}\text { (1 - Very Low } \\
2 \text { - Low } \\
3 \text { - Medium } \\
4 \text { - High } \\
5 \text { - Very High) }\end{array}$ & \\
\hline $\begin{array}{l}\text { Day-to-day Power } \\
\text { Demand Variation }\end{array}$ & $\begin{array}{l}\text { (1 - Very High } \\
2 \text { - High } \\
3 \text { - Medium } \\
4 \text { - Low } \\
5 \text { - Very Low) }\end{array}$ & \\
\hline Typical Peak Season & $\begin{array}{l}\text { (January - April } \\
\text { May - October } \\
\text { October - December } \\
\text { Other Peak [please specify in } \\
\text { comments] } \\
\text { No Peak) }\end{array}$ & \\
\hline Production Type & $\begin{array}{l}\text { (1 - Continuous Process } \\
2 \text { - Mixed Batch/Continuous } \\
\text { Process } \\
3 \text { - Batch Process } \\
4 \text { - Continuous Manufacturing } \\
5 \text { - Mixed Batch/Continuous }\end{array}$ & \\
\hline
\end{tabular}




\begin{tabular}{|c|c|c|}
\hline & $\begin{array}{l}\text { Manufacturing } \\
6 \text { - Batch Manufacturing) }\end{array}$ & \\
\hline Process Interruptibility & $\begin{array}{l}\text { (1 - Not Interruptible } \\
2 \text { - Somewhat Interruptible } \\
3 \text { - Interruptible) }\end{array}$ & \\
\hline Shed Ability (\% of peak) & $\begin{array}{l}0-10 \% \\
10-25 \% \\
25-50 \% \\
50-75 \% \\
75-100 \%)\end{array}$ & \\
\hline \multicolumn{3}{|c|}{ Energy Efficiency and Demand Response Questions } \\
\hline Attribute & Rating & Comments \\
\hline $\begin{array}{l}\text { Typical Energy } \\
\text { Management Decision } \\
\text { Makers }\end{array}$ & $\begin{array}{l}\text { (Corporate Manager } \\
\text { Plant Manager } \\
\text { Production Manager } \\
\text { Facilities Manager } \\
\text { Maintenance Supervisor } \\
\text { Systems Operator } \\
\text { Other) }\end{array}$ & \\
\hline $\begin{array}{l}\text { Typical Level of } \\
\text { Adoption of Energy } \\
\text { Efficiency Measures }\end{array}$ & $\begin{array}{l}\text { (1 - Very Low } \\
2 \text { - Low } \\
3 \text { - Medium } \\
4 \text { - High } \\
5 \text { - Very High) }\end{array}$ & \\
\hline Past DR participation & $\begin{array}{l}\text { (Not Likely } \\
\text { Likely } \\
\text { Very Likely) }\end{array}$ & \\
\hline
\end{tabular}

